\section{Flowering Phenology of Eastern Filbert Blight-resistant Hazelnut Accessions in New Jersey}

\author{
John M. Capik ${ }^{1}$ and Thomas J. Molnar ${ }^{1,2}$
}

AdDitional Index wORDs. Anisogramma anomala, Corylus avellana, Corylus americana, disease resistance, nut crops, pollinizer, tree breeding

SumMary. Hazelnuts (Corylus sp.) are monoecious and wind-pollinated with reproduction limited by a sporophytic self-incompatibility system. They flower during the winter and are dichogamous with the dates of flowering ranging from December to March in New Jersey depending on the genotype, geographic location, and year. Successful, consistent nut production depends on both genetic compatibility and the appropriate timing of flowering between pollinizing and nutproducing cultivars. While the disease eastern filbert blight (EFB), caused by Anisogramma anomala, has severely limited past hazelnut production in the eastern United States, resistant and tolerant genotypes are now available for testing. However, little is known of their flowering phenology in this region. In this study, the flower and budbreak phenology of 19 different EFB-resistant and EFB-tolerant hazelnut accessions was evaluated over 4 years, and the results compared with air temperature data collected during bloom. Results showed that the accessions followed a similar progression of bloom each year (both staminate and pistillate flowers), which allowed their placement into early-, mid-, and late-flowering groups. However, the date of bloom and duration of bloom, especially for pollen shed, differed each year, largely corresponding to average air temperature trends. Confirming previous reports from other cold regions, it was shown that consistently colder average temperatures delayed bloom until later in the winter, which then led to a compressed period of flowering once temperatures warmed. In contrast, relatively warm temperatures over the season led to earlier flowering as well as a significant lengthening of the duration of bloom, similar to responses reported in Mediterranean climates. Our study documents hazelnut flowering phenology under New Jersey's variable winter climate, and the results provide a benchmark for selecting suitable pollenizers and breeding parents for future nut production, flowering research, and/or genetic improvement in this region.

$\mathrm{E}$ uropean hazelnut (Corylus avellana) is an important world agricultural crop, ranking fifth in overall tree nut production. Turkey produced $430,000 \mathrm{t}$ of hazelnuts in 2011 , accounting for $\approx 58 \%$ of total world production $(742,997 \mathrm{t}$ in 2011$)$, followed by Italy $(128,940 \mathrm{t})$, the United States [34,927 t $(\approx 5 \%)]$, Azerbaijan $(32,922 \mathrm{t})$, and the Republic of Georgia $(31,100$ t) (Food and Agriculture Organization of the United Nations, 2013). Commercial production in the United States takes place almost solely in the Willamette Valley

Funding comes from the New Jersey Agricultural Experiment Station, the Rutgers Center for Turfgrass Science, Hatch funds provided by USDA-NIFA, and the USDA-NIFA Specialty Crops Research Initiative Competitive Grant 2009-51181-06028.

We would like to thank C.R. Funk and S. Mehlenbacher for their contributions to this study.

${ }^{1}$ Department of Plant Biology and Pathology, Rutgers University, 59 Dudley Road, Foran Hall, New Brunswick, NJ 08901

${ }^{2}$ Corresponding author. E-mail: molnar@aesop.rutgers. edu.
Thompson et al., 1996). The absence of this pathogen combined with a mild climate allowed hazelnut production to flourish in the Pacific Northwest for nearly a century (Thompson et al., 1996). However, EFB was inadvertently introduced into southwestern Washington in the late 1960s. The resulting disease devastated hazelnut orchards in the state, as control methods were not yet established (Cameron, 1976; Davison and Davidson, 1973).

Although it was later learned that scouting for cankers, therapeutic pruning, and copious fungicide applications could keep the disease under control (Johnson et al., 1996), due to their associated expenses, the most cost-effective and sustainable approach for long-term management was considered to be using and developing genetic resistance to the pathogen (Julian et al., 2009; Mehlenbacher, 1994; Thompson et al., 1996). In the 1970s, 'Gasaway' european hazelnut, an obsolete, late-blooming pollenizer, was found to be resistant to EFB. It was later shown to transmit this resistance to its offspring in a manner indicative of a dominant allele at a single locus (Mehlenbacher et al., 1991). 'Gasaway' has since been widely used in the Oregon State University (OSU) breeding program. To date, a number of cultivars carrying the gene have been released, including Yamhill (Mehlenbacher et al., 2009), Jefferson (Mehlenbacher et al., 2011), and Dorris (Mehlenbacher et al., 2013), as well as various pollenizers (Mehlenbacher and Smith, 2004; Mehlenbacher and Thompson, 1991; Mehlenbacher et al., 2012). These new cultivars have reinvigorated the hazelnut industry in Oregon, which, after decades of decline, has been expanding at a rate of about 1200 ha per year for the past 5 years (S.A. Mehlenbacher, personal communication).

In addition to 'Gasaway', a number of other sources of EFB resistance have also been identified at OSU and Rutgers University and are currently being used in breeding (Capik et al., 2013; Chen et al., 2007; Lunde et al., 2000; Molnar et al., 2009, 2010;

\begin{tabular}{llll}
\hline $\begin{array}{l}\text { Units } \\
\begin{array}{l}\text { To convert U.S. to SI, } \\
\text { multiply by }\end{array}\end{array}$ & U.S. unit & SI unit & $\begin{array}{l}\text { To convert SI to U.S., } \\
\text { multiply by }\end{array}$ \\
\hline 0.4047 & acre $(\mathrm{s})$ & ha & 2.4711 \\
0.9072 & ${ }^{\circ}(\mathrm{s})$ & $\mathrm{t}$ & 1.1023 \\
$\left({ }^{\circ} \mathrm{F}-32\right) \div 1.8$ & ${ }^{\circ} \mathrm{F}$ & ${ }^{\circ} \mathrm{C}$ & $\left({ }^{\circ} \mathrm{C} \times 1.8\right)+32$
\end{tabular}

Hortlechnology · April 2014 24(2) 
Sathuvalli et al., 2010). Capik and Molnar (2012) examined the disease response of 190 clonal accessions of hazelnut, including multiple hazelnut species and interspecific hybrids from a wide diversity of origins, in $\mathrm{New}$ Jersey. While some plants previously reported as resistant to EFB in Oregon developed disease, including 'Gasaway' and some of its offspring, a large number of the accessions remained resistant or highly tolerant to EFB in New Jersey over more than 10 years of exposure.

Today, with access to a multitude of EFB-resistant cultivars and breeding selections, one of the major impediments to developing a commercial hazelnut industry in parts of eastern United States has been greatly diminished. As such, it is important to examine other factors critical to consistent hazelnut production in this region. Because nut production is fully dependent on successful cross pollination, one factor of vital importance is flowering - a topic poorly studied and documented for hazelnut in the eastern United States.

Hazelnuts are monoecious, windpollinated, and self-incompatible. Reproduction is restricted by a sporophytic self-incompatibility system, which is controlled by a single locus with various $\mathrm{S}$-alleles determining compatibility (Mehlenbacher, 1997; Olsen et al., 2000; Thompson, 1979). Over 30 $S$-alleles have been identified to date (S.A. Mehlenbacher, personal communication). Dominance or codominance of the alleles is expressed in the pollen, whereas all known S-alleles are codominant in the pistil (Mehlenbacher, 1997; Mehlenbacher and Thompson, 1988).

Hazelnuts are also dichogamous. Male (catkins, staminate) and female (pistillate) flowers have different chilling requirements to break dormancy, with catkins typically having lower chilling requirements than the female flowers [ranges of 100-860 $\mathrm{h}$ and 290$1550 \mathrm{~h}$, respectively (Mehlenbacher, 1991)]. Normal flowering occurs in winter before vegetative budbreak, over a range of dates depending on the genotype, geographic location, and year. In traditional hazelnutproducing regions, most of which are primarily located adjacent to large bodies of water, which moderate their climate hazelnuts can bloom over an extended period from early December through March. In colder regions, bloom is compressed over a much shorter time frame in late winter or early spring in response to warming temperatures (Črepinšek et al., 2012; Germain, 1994; Olsen et al., 2000; Piskornik et al., 2001; Solar and Stampar, 2009; Thompson et al., 1996). Plants are typically either protandrous or protogynous depending on their genetic background and the climate of the region they are grown in. In regions with mild climates, protandry seems to be more common, whereas in regions with long, cold winters, protogynous or homogamous flowering typically occurs (Germain, 1994; Mehlenbacher, 1991; Olsen et al., 2000; Piskornik et al., 2001).

Female flowers are unique in that, if not pollinated, stigmatic surfaces can stay receptive to fertilization for up to 3 months (Thompson, 1979). When compatible pollen reaches a receptive female flower, the pollen grain germinates and develops a germ tube, which grows down to the base of the style where the sperm cell subsequently travels and then rests. At this time, the ovary is not yet fully formed. After ovary formation is complete, usually in late spring, the pollen tubes begin to grow again and fertilization occurs (Beyhan and Marangoz, 2007).

Differences in cold tolerance have also been reported for male and female flowers. In controlled freezing tests, Hummer et al. (1986) showed that female flowers of some european hazelnut cultivars could survive temperatures below $-40{ }^{\circ} \mathrm{C}$. However, catkins were shown to be injured at warmer temperatures. The most coldtolerant, fully dormant catkins tested were hardy to $-35^{\circ} \mathrm{C}$, although some cultivars (e.g., Ennis, Tonda Romana) displayed injury at temperatures reaching only $-15{ }^{\circ} \mathrm{C}$ (Hummer et al., 1986). Catkins elongating before anthesis or fully elongated and shedding pollen were not tested. However, it should be noted that past experience of the authors suggests that elongating or shedding catkins are much more susceptible to cold damage than fully dormant ones (data not shown). Thus, in cold regions with unpredictable winter climates, such as that found across the mid-Atlantic region of the eastern United States, catkin survivability can present a significant challenge for consistent nut production. Once chilling requirements are met, the occurrence of atypical warm winter weather can signal the catkins to elongate prematurely, making them more sensitive to cold damage. This problem can be exacerbated by high winter winds, not uncommon in the eastern United States, which appear to cause desiccation injury (Reed and Davidson, 1958; Slate, 1933). Past reports suggest that hazelnuts may appear to thrive in the eastern United States but fail to produce nuts because of catkin damage and lack of pollination (MacDaniels, 1964).

The density of pollenizers in orchards around the world ranges from $3 \%$ to $30 \%$, with $10 \%$ pollenizer density as the standard in Oregon (Olsen et al., 2000). Recent recommendations in Oregon include planting at least three different pollenizers that shed pollen at different times during the period that female flowers of the main crop cultivar are receptive to ensure consistent orchard pollination (Mehlenbacher et al., 2009). In respect to meeting this recommendation, very little research has been done to document how fluctuating winter temperatures affect flowering phenology of hazelnut in the eastern United States. For example, over a $10-\mathrm{d}$ period from 22 Dec. 2008 to 1 Jan. 2009, winter temperatures in New Brunswick, NJ, varied from -11.1 to $18.9{ }^{\circ} \mathrm{C}$, then back to $-8.3{ }^{\circ} \mathrm{C}(\mathrm{Na}-$ tional Climate Data Center, 2013). Knowledge of how hazelnuts respond under these conditions is vital to developing orchards that produce nuts on a consistent yearly basis.

The objective of this study was to evaluate the flower and budbreak phenology of 19 different EFB-resistant and EFB-tolerant hazelnut cultivars and breeding selections over 4 years to better understand their response to New Jersey's climate and to provide a benchmark for selecting suitable pollenizers and breeding parents in the future.

\section{Materials and methods}

Plant material. Nineteen cultivars and clonal breeding selections, representing various sources of EFBresistance and disparate genetic backgrounds (Table 1), were observed over a period of 4 years to determine the timing of their pollen shed, pistillate flower emergence, and vegetative budbreak. The trees were originally propagated at Rutgers University with 
Table 1. Hazelnut accessions evaluated for flowering and budbreak phenology in New Jersey over the winter seasons of 2008-09 through 2011-12.

\begin{tabular}{|c|c|c|c|}
\hline Accession $^{\mathrm{z}}$ & Trees (no.)-planting yr & Origin/parentage & $\begin{array}{l}\text { Incompatibility } \\
\text { alleles }^{\mathrm{y}}\end{array}$ \\
\hline 'Ratoli' & $2-2002$ & Spain (Tarragona), PI 557167 & $S_{2}, S_{10}$ \\
\hline 'Tonda di Giffoni' & $3-2002$ & Italy (Campania), PI 296207 & $\mathrm{~S}_{2}, \overline{\mathrm{S}_{23}}$ \\
\hline 'Closca Molla' & $2-2002$ & Spain (Tarragona), PI 557109 & $S_{2}, \overline{S_{\underline{5}}}$ \\
\hline $\begin{array}{l}\text { Oregon State University } \\
\quad(\text { OSU }) 541.147\end{array}$ & $3-2002$ & $\begin{array}{l}\text { Oregon, 'NY 110' (Corylus americana } \\
\text { 'Rush' } \times \text { Corylus avellana 'DuChilly') } \\
\times \text { OSU } 226.118\end{array}$ & $S_{\underline{8}}, S_{\underline{23}}^{-}$ \\
\hline 'Delta' & $\begin{array}{l}1-2003 \\
2-2006\end{array}$ & Oregon, OSU $249.159 \times$ VR $17-15$ & $S_{\underline{1}}^{-}, S_{\underline{15}}$ \\
\hline OSU 526.041 & $3-2002$ & Oregon, C. heterophylla 'Ogyoo' $\times$ C. avellana & Unknown \\
\hline VR 20-11 & $3-2002$ & Oregon, [('Barcelona' × 'Compton') × 'Gasaway'] & $S_{2}, S_{\underline{3}}$ \\
\hline 'Santiam’ & $3-2006$ & Oregon, OSU $249.159 \times$ VR $17-15$ & $\mathrm{~S}_{\underline{3}}, \mathrm{~S}_{15}^{-}$ \\
\hline OSU 495.072 & $3-2002$ & Russia (southern) & $\mathrm{S}_{\underline{6}}^{-}, \mathrm{S}_{30}$ \\
\hline NADF \#l (10-50) & $3-2005$ & Nebraska, National Arbor Day Foundation selection & Unknown \\
\hline 'Estrella \#1' & $3-2006$ & $\begin{array}{l}\text { Michigan, Corylus heterophylla var. sutchuenensis } \times \\
\text { C. avellana 'Holder', PI 557351 }\end{array}$ & Unknown \\
\hline OSU 587.044 & $2-2002$ & $\begin{array}{l}\text { Oregon, Corylus californica B0509 × OSU } 278.113 \\
\quad \text { ('Tombul Ghiaghli' } \times \text { INRA H 105-28) }\end{array}$ & $S_{2}, S_{\underline{Z}}$ \\
\hline Finland CCOR 187.001 & $3-2006$ & Finland, PI 557080 & $S_{9}, S_{\underline{25}}$ \\
\hline 'Gasaway’ & $3-2002$ & Washington, PI 557042 & $S_{\underline{3}}, \overline{S_{26}}$ \\
\hline OSU 408.040 & $3-2002$ & Minnesota, PI 617266 & $\mathrm{~S}_{\underline{20}}, \mathrm{~S}_{27}$ \\
\hline
\end{tabular}

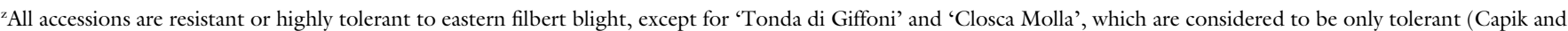
Molnar, 2012). Plants are listed from top to bottom in the general order in which they flowered each year.

yominant alleles for each accession are underlined.

scion wood provided by OSU or the U.S. Department of Agriculture (USDA) Agricultural Research Service National Clonal Germplasm Repository, Corvallis, OR, except for NADF \# 1 provided by the National Arbor Day Society, Nebraska City, NE. All of the trees were planted from 2002 to 2006 at the Rutgers University Horticultural Research Farm 3, North Brunswick, NJ, with specific planting dates listed in Table 1. A majority of the cultivars in the study were represented by three trees each, although OSU 587.044, 'Closca Molla', and 'Ratoli' were represented by two trees each, and 'Epsilon' and 'Gamma' only by one each.

Assessment OF FLOWER AND VEGETATIVE BUDBREAK PHENOLOGY. During the winter and early spring periods of 2008-09 through 201112 , observations of catkin and female flower development and vegetative budbreak were made and recorded twice weekly (every 3-4 d) from late December through mid-April. Catkin developmental stages were rated on a scale of 1 to 3 (Fig. 1), similar to that

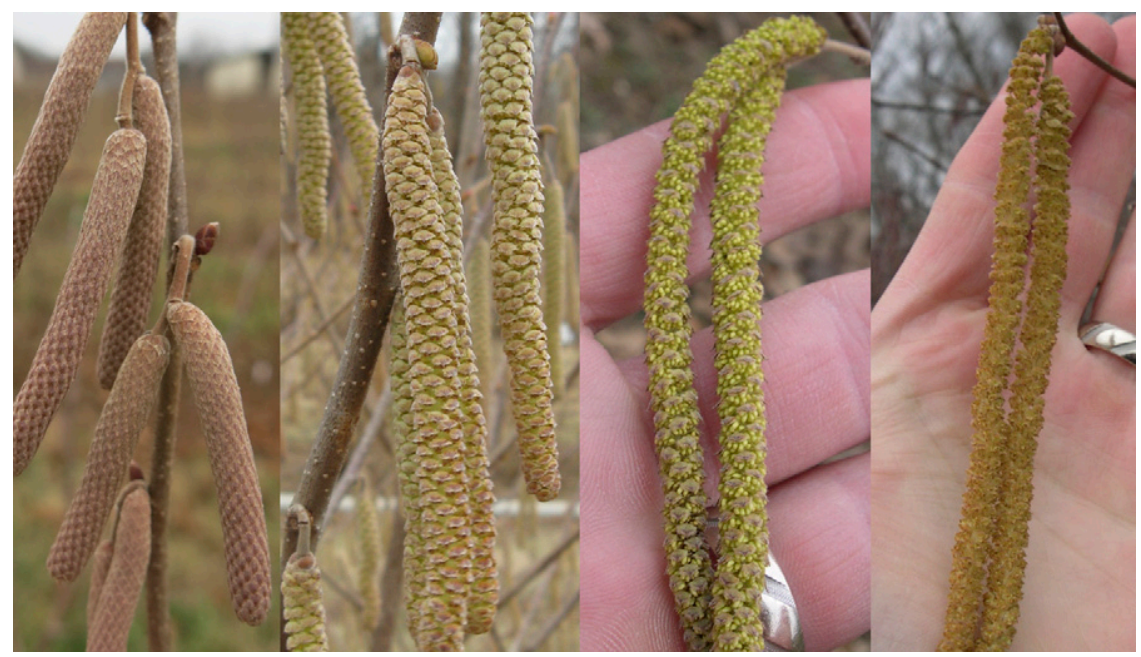

Fig. 1. Progression of hazelnut staminate flower development. From left to right: dormant catkins, Stage 1 (catkin begins elongation), Stage 2 (full elongation, peak pollen shed), and Stage 3 (anthers dry out, pollen shed ends). Pictures are not to scale.

developed by Germain and Sarraquigne (2004). Stage 1 occurs when catkin elongation is initiated and is represented by only minor pollen shed. Catkins were considered to have reached this stage as soon as any sign of stretching was apparent, which signifies a break in dormancy. Catkins reach Stage 2 when elongation achieves its maximum point and significant pollen shed is taking place. Catkins were considered to have reached this stage when, upon inspection, a considerable amount of pollen was visibly released 


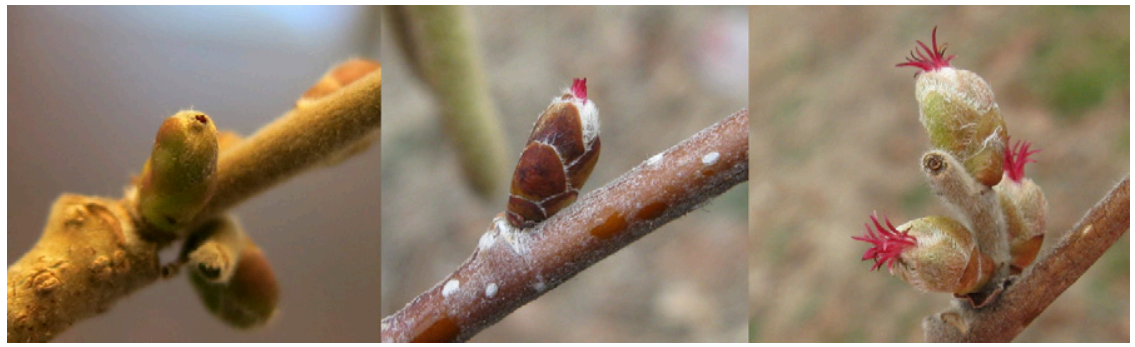

Fig. 2. Progression of hazelnut pistillate flower development. From left to right: Stage 1 (red dot stage), Stage 2 (intermediate stage), and Stage 3 (full spider stage). Stage 4 is reached when $>\mathbf{5 0 \%}$ of all female flowers on the tree are in the "full spider" stage. Pictures are not to scale.

when the catkin was tapped with one's finger. Stage 2 was deemed the period of peak pollen shed. Stage 3 occurs when peak pollen shed concludes and the anthers within the catkins appear dry and withered, although minute amounts of pollen continue to be released for several days afterward.

Female flower developmental stages were rated on a scale of 1 to 4 (Fig. 2), also similar to that developed by Germain and Sarraquigne (2004). It should be noted that this scale is not considered to be absolute, as not all flowers on one tree progress at the same rate. Phenology ratings were taken on female flowers present on typical, mature branches and represent the stage in which a large majority of the flowers were in at the time of the rating. Stage 1, or the "red dot" stage, occurs when a single "dot" of red or purple color is observed emerging from the center of the floral buds. Stage 2 happens when the styles begin to noticeably emerge from the buds. The individual styles point straight out at this stage and have only just begun to separate. Stage 3 occurs when the styles on the most advanced floral buds are fully exserted and begin to bend away from the center. The fully exserted styles have been referred to as "full spiders" at this stage because of their superficial resemblance to arachnids (R. McCloskey, personal communication). Stage 4 is reached when greater than $50 \%$ of female flower are in the "full spider" stage. It should be noted that stigmas are receptive to pollen at all stages of exsertion (Thompson et al., 1996).

Vegetative budbreak was recorded as the date that vegetative buds began to visibly swell, with clear separation of the bud scales, which indicates a breaking of dormancy. Although vegetative budbreak does progress through several stages up until full leaf development (Germain and Sarraquigne, 2004), and this information was observed and recorded, only the initial point of clearly breaking dormancy (Stage 1) was considered of most interest and discussed as part of the results in this study.

D A T A A N A L Y S I S A N D PRESENTATION. The calendar dates when the male and female flowers (and vegetative buds) entered into each phenological stage, as described above, were converted to the number of days since the start of the calendar year (e.g., 3 Jan. = 3, 3 Feb. = 33). These numbers were then averaged across the replicates of each cultivar/ breeding selection to present the average date each cultivar/breeding selection reached that particular stage. This was repeated for each year of the study. The 4-year average was then calculated by taking the average date of progression into each stage for all trees per cultivar/breeding selection across all years. Individual years and the 4-year average were then graphically represented to help visualize the differences between the accessions and the year-to-year variation (Figs. 3-7). The complete set of phenology data can be found in Supplemental Table 1.

Temperature data. Maximum and minimum daily air temperature data were obtained from the New Brunswick 3 SE weather station in New Brunswick, NJ, located less than I mile from the Rutgers University Horticultural Farm 3 (National Climate Data Center, 2013). Mean daily temperatures were estimated by taking the average of the minimum and maximum daily temperature recorded for each day. The 4-year mean daily temperatures were estimated by averaging all mean temperatures for each day of the 4-year study. It was previously shown that hazelnut phenology correlates better with daily mean and maximum temperatures than minimums (Crepinšek et al., 2012). Thus, estimated mean daily temperatures were included in the final phenology diagrams to provide a display of temperature trends across each year (and then the average of 4 years) for comparison between years and for discussion of phenology results.

\section{Results and discussion}

The average floral and budbreak phenology for each accession over the past 4 years is shown in Fig. 3 with averages for each individual year shown in Figs. 4-7. Individual dates for each tree per year are shown in Supplemental Table 1. Overall, whereas the dates of male and female anthesis and vegetative budbreak differed for each accession from year to year, the results show that the accessions tended to follow a similar, consistent pattern in their progression. Based on this repeating pattern, accessions were placed into early-, mid-, and late-flowering groups (Tables 2-4). These groupings held true over all 4 years with only minor variation within and among them, and they were largely similar across their respective male and female flowers and vegetative bud groups, as discussed in more detail below.

\section{Catkin development (pollen shed)}

EARLY GROUP. 'Tonda di Giffoni' (TdG), 'Estrella \#l', and 'Ratoli' were consistently the earliest accessions to shed pollen each year. Their 4-year average dates of reaching Stage 1 were 23 Jan., 29 Jan., and 6 Feb., respectively (Table 2 ), although some yearto-year variation of this pattern was observed (Figs. 4-7). TdG was usually the first and held the record for the earliest initial pollen shed observed during the course of the study (Stage 1 on 20 Dec. 2011). It should be noted that catkins of TdG were estimated to have a chilling requirement between 170-240 $\mathrm{h}$ by Mehlenbacher (1991), which was among the lowest of the cultivars tested. In Oregon, its first observed pollen shed date was 15 Jan., $8 \mathrm{~d}$ earlier than the average Stage 1 date in New Jersey. In general, 1 week separated the average Stage 1 


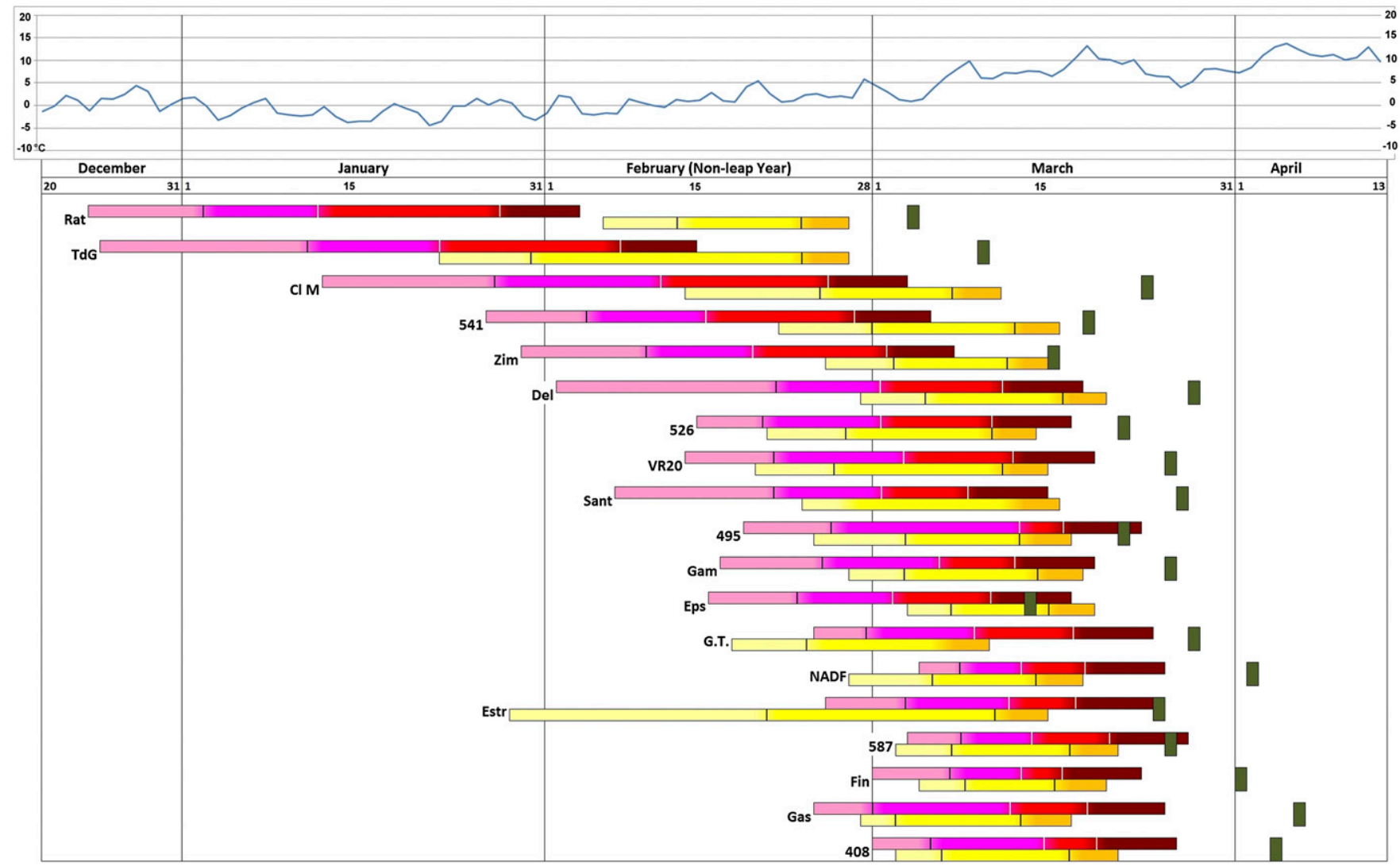

Fig. 3. Graphical summary of the phenological development of the staminate and pistillate flowers and vegetative buds of 19 hazelnut accessions over 4 years in North Brunswick, NJ. The yellow bars represent staminate flower development. The gradient of three yellow colors corresponds to the stages of development described in the manuscript (light yellow is Stage 1, yellow is Stage 2, and dark yellow is Stage 3. The pink/red bars represent pistillate flower development. Pink corresponds to Stage 1, magenta to Stage 2, red to Stage 3, and maroon to Stage 4. Stage 1 of vegetative bud development is represented by a green square. Estimated daily average temperatures, which were calculated by averaging the daily high and low temperatures, are presented across the top of the figure. Accessions from top to bottom: 'Ratoli' (Rat), 'Tonda di Giffoni' (TdG), 'Closca Molla' (Cl M), OSU 541.147 (541), 'Zimmerman' (Zim), 'Delta' (Del), OSU 526.041 (526), OSU VR 20-11 (VR20), 'Santiam' (Sant), OSU 495.072 (495), 'Gamma' (Gam), 'Epsilon' (Eps), 'Grand Traverse' (G.T.), NADF \#1 (NADF), 'Estrella \# 1' (Estr), OSU 587.044 (587), Finland CCOR 187 (Fin), 'Gasaway' (Gas), and OSU 408.040 (408). Four-year average flower and bud development for 19 hazelnut accessions between Dec. 2008 and Apr. 2012; $\left(1.8 \times{ }^{\circ} \mathrm{C}\right)+32={ }^{\circ} \mathrm{F}$.

bloom date of 'Ratoli', the latest plant from this group, from 'Closca Molla' (average date of Stage 1 was 13 Feb.), the earliest plant from the mid group, discussed subsequently (Table 2 ).

Mid group. 'Closca Molla', 'Grand Traverse', VR 20-11, OSU 526.041, OSU 541.147, 'Santiam', OSU 495.072, 'Zimmerman', 'Gamma', NADF \#1, and 'Delta' consistently bloomed within close proximity to one another, largely in the order presented (Table 2). This grouping stayed very consistent over all 4 years, with a few exceptions. The earliest pollen shed for any of these accessions was in the 2011-12 bloom period, when 'Grand Traverse' reached Stage 1 on 30 Jan. (Fig. 7). This early bloom was reflected in the fact that this period had the highest average monthly temperatures recorded for both December $\left(4.8^{\circ} \mathrm{C}\right)$ and January $\left(1.5^{\circ} \mathrm{C}\right)$ over the course of the study (Table 5 ). The latest blooming accession included in the mid group to reach Stage 1 over the 4 years was 'Gamma' on 6 Mar. 2009. This was also on the same date as 'Epsilon' and later than OSU 587.044 and OSU 408.040, which were generally very late blooming and are discussed below as part of the late group.

LATE Group. 'Gasaway', OSU 408.040, OSU 587.044, 'Epsilon', and Finland CCOR 187 were consistently the latest group of plants to shed pollen and generally followed the order presented. These accessions typically did not reach Stage 1 until the first week of March, $5 \mathrm{~d}$ after the last accession included in the mid group [NADF \#1, average date 27 Feb. (Table 2)]. A member of this late group was always the last accession to reach Stage 1 each year. The latest record of any accession reaching Stage 1 was observed on 6 Mar. 2012 with OSU 587.044. In contrast, the earliest pollen shed by a member of this group, other than the anomalous 'Gasaway' behavior described in the following paragraph, was 28 Feb. 2009 by OSU 408.040 and 28 Feb. 2012 by Finland CCOR 187. On occasion, an accession from the mid group would overlap Stage 1 with one of these five accessions, like NADF \# 1 and 'Gamma' in the 200809 period and 'Gamma', 'Santiam', 'Delta', and 'Zimmerman' in the 200910 period. However, on average across all years and accessions, plants from the late group began Stage 1 nine days after plants from the mid group (Table 2). 


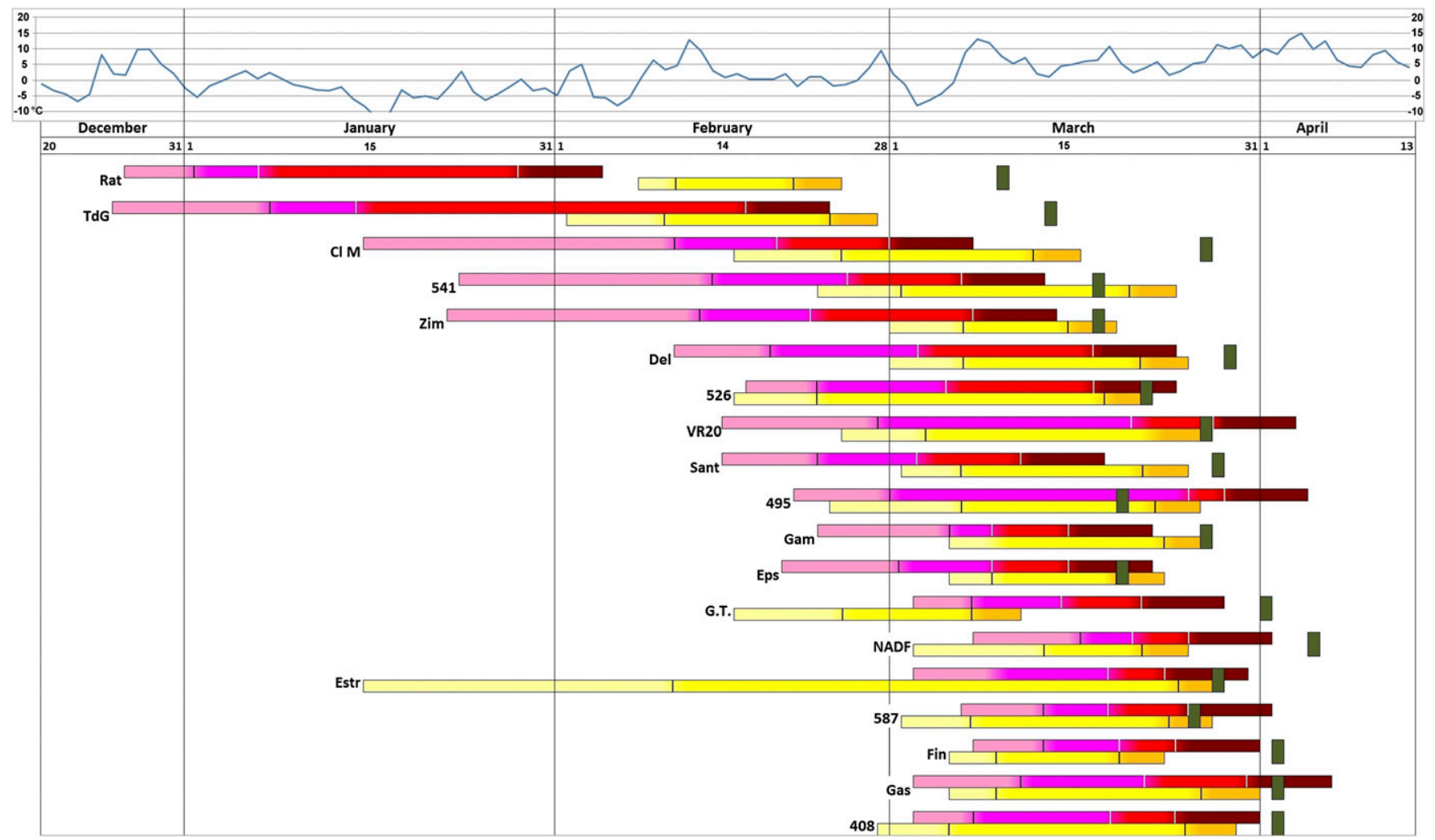

Fig. 4. Flower and bud development for 19 hazelnut accessions between Dec. 2008 and Apr. $2009 ;\left(1.8 \times{ }^{\circ} \mathrm{C}\right)+32={ }^{\circ} \mathrm{F}$. See Figure 3 caption for full description.

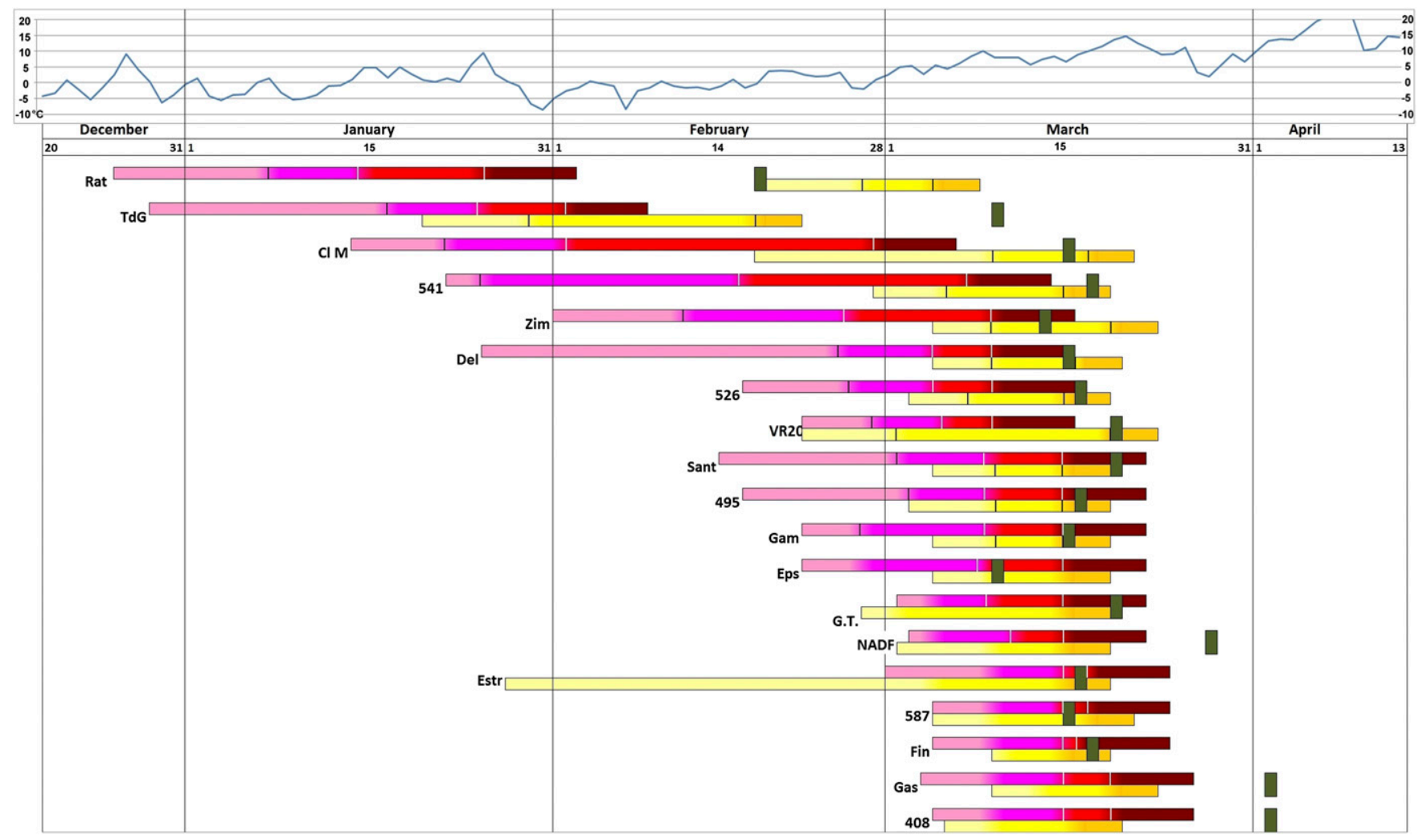

Fig. 5. Flower and bud development for 19 hazelnut accessions between Dec. 2009 and Apr. $2010 ;\left(1.8 \times{ }^{\circ} \mathrm{C}\right)+32={ }^{\circ} \mathrm{F}$. See Figure 3 caption for full description. 


\section{Research Reports}

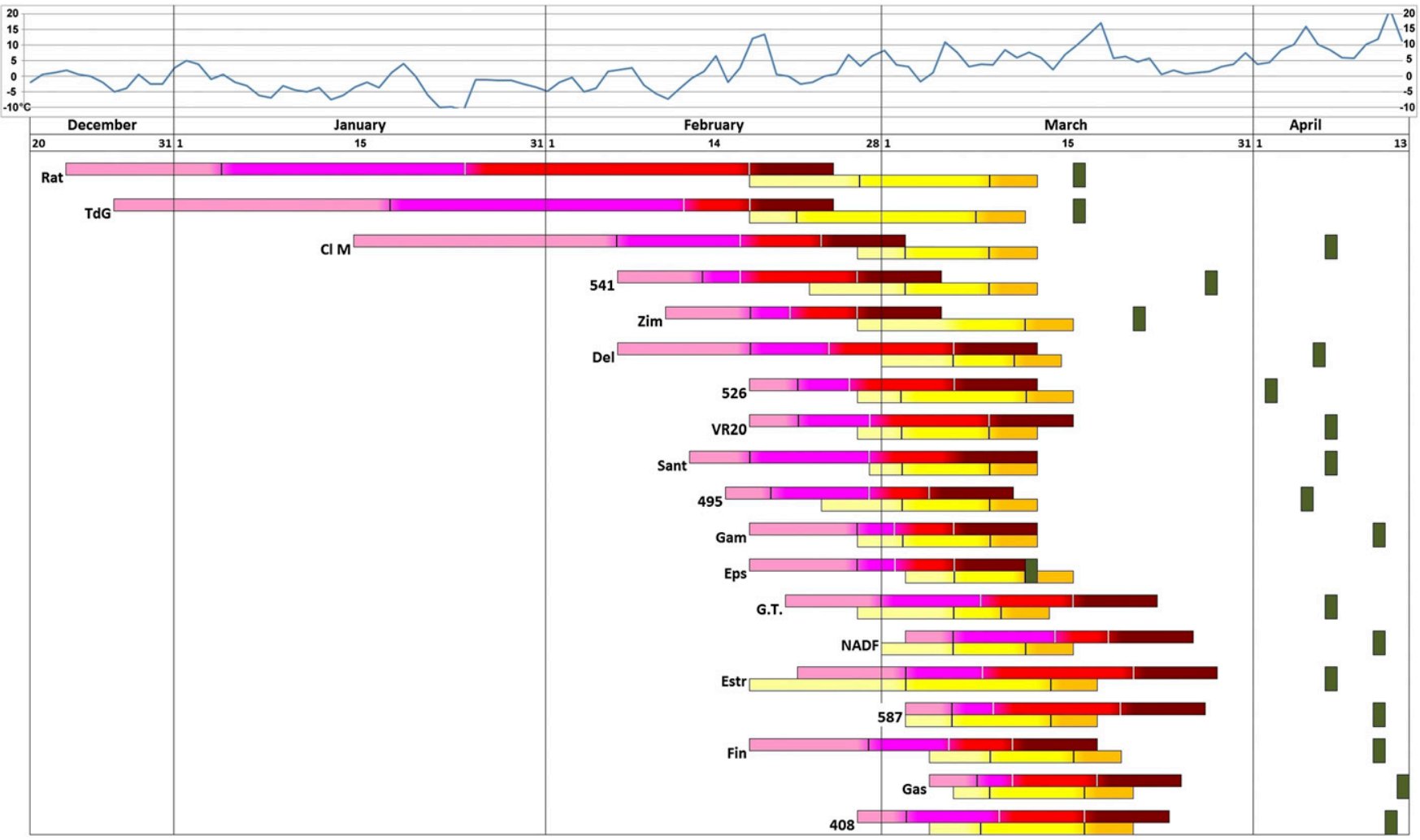

Fig. 6. Flower and bud development for 19 hazelnut accessions between Dec. 2010 and Apr. 2011. This period represents the overall coldest bloom period of the 4 -year study; $\left(1.8 \times{ }^{\circ} \mathrm{C}\right)+32={ }^{\circ} \mathrm{F}$. See Figure 3 caption for full description.

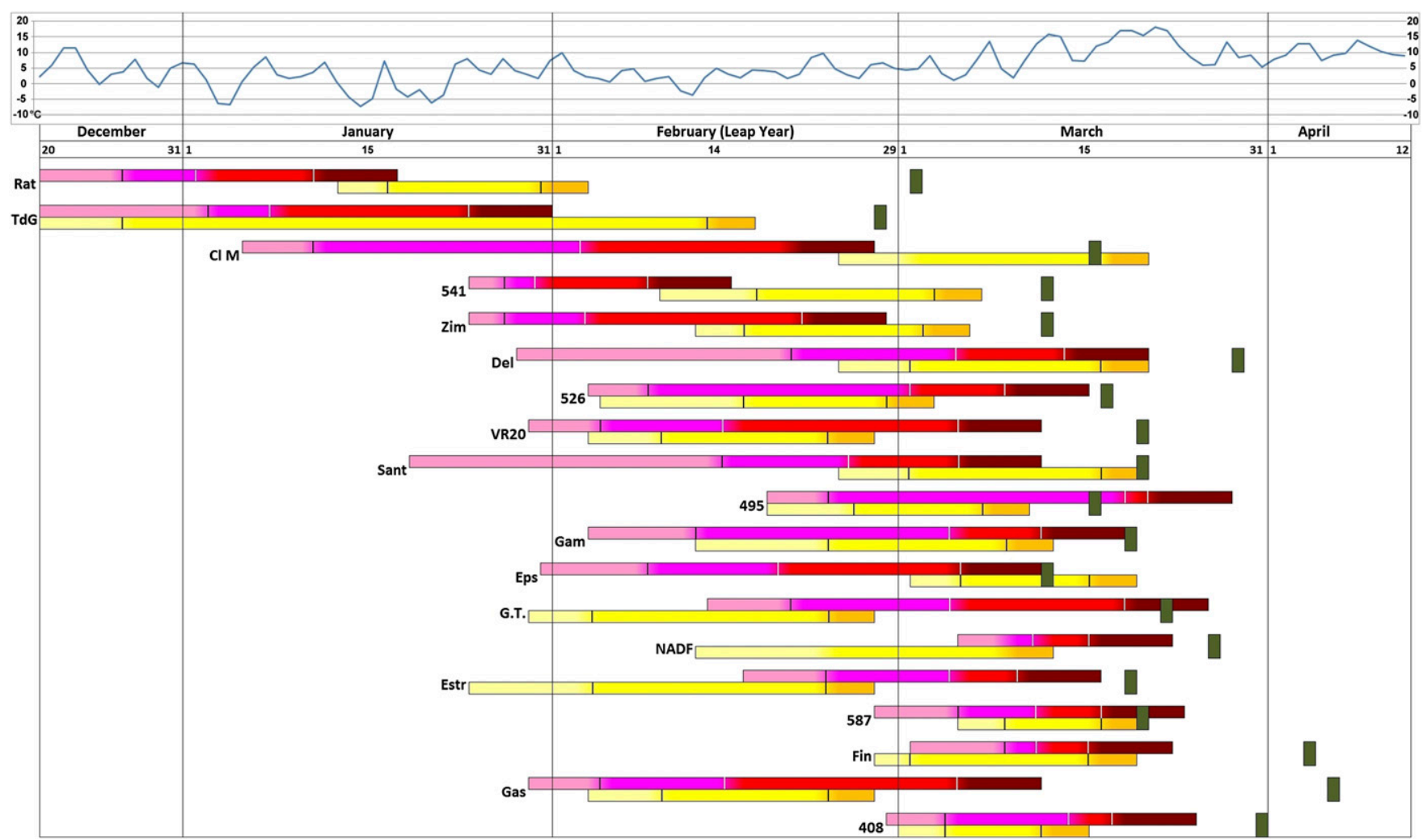

Fig. 7. Flower and bud development for 19 hazelnut accessions between Dec. 2011 and Apr. 2012. This period represents the overall warmest bloom period of the 4 -year study; $\left(1.8 \times{ }^{\circ} \mathrm{C}\right)+32={ }^{\circ} \mathrm{F}$. See Figure 3 caption for full description. 
Table 2. Summary of staminate flower development (Stage 1-3) for 19 hazelnut accessions averaged across 4 years in New Jersey.

\begin{tabular}{|c|c|c|c|c|c|c|c|}
\hline \multirow[b]{2}{*}{ Group } & \multirow[b]{2}{*}{ Accession } & \multicolumn{2}{|c|}{ Stage 1} & \multicolumn{2}{|c|}{ Stage 2} & \multirow{2}{*}{$\frac{\text { Stage } 3}{\text { Date }}$} & \multirow[b]{2}{*}{ Total duration $(\mathrm{d})$} \\
\hline & & Date & Duration $(\mathrm{d})$ & Date & Duration (d) & & \\
\hline \multirow[t]{2}{*}{ Early } & 'Tonda di Giffoni' & 23 Jan. & 7 & 31 Jan. & 17 & 23 Feb. & 24 \\
\hline & 'Ratoli' & 6 Feb. & 6 & 13 Feb. & 11 & 23 Feb. & 17 \\
\hline \multirow[t]{6}{*}{ Mid } & 'Closca Molla' & 13 Feb. & 11 & 25 Feb. & 12 & 8 Mar. & 23 \\
\hline & OSU 526.041 & 20 Feb. & 7 & 27 Feb. & 13 & 11 Mar. & 21 \\
\hline & OSU 541.147 & 21 Feb. & 7 & 29 Feb. & 13 & 13 Mar. & 20 \\
\hline & 'Santiam’' & 23 Feb. & 4 & 27 Feb. & 15 & 13 Mar. & 19 \\
\hline & OSU 495.072 & 24 Feb. & 8 & 4 Mar. & 10 & 14 Mar. & 19 \\
\hline & 'Zimmerman' & 25 Feb. & 6 & 3 Mar. & 10 & 13 Mar. & 16 \\
\hline \multirow[t]{5}{*}{ Late } & ‘Gasaway’ & 28 Feb. & 4 & 3 Mar. & 11 & 14 Mar. & 15 \\
\hline & OSU 408.040 & 3 Mar. & 4 & 7 Mar. & 11 & 18 Mar. & 15 \\
\hline & OSU 587.044 & 3 Mar. & 5 & 8 Mar. & 11 & 19 Mar. & 16 \\
\hline & 'Epsilon’ & 4 Mar. & 4 & 8 Mar. & 8 & 16 Mar. & 13 \\
\hline & Finland CCOR 187 & 5 Mar. & 4 & 9 Mar. & 8 & 16 Apr. & 12 \\
\hline \multirow[t]{4}{*}{ Averages } & Early group avg & 30 Jan. & 12 & 11 Feb. & 16 & 29 Feb. & 28 \\
\hline & Mid group avg & 22 Feb. & 7 & 29 Feb. & 12 & 12 Mar. & 19 \\
\hline & Late group avg & 3 Mar. & 4 & 7 Mar. & 10 & 23 Mar. & 14 \\
\hline & Overall avg & $21 \mathrm{Feb}$. & 7 & $28 \mathrm{Feb}$. & 12 & 13 Mar. & 19 \\
\hline
\end{tabular}

It should be noted that, in the 2011-12 period, 'Gasaway' reached Stage 1 during the first week of February (Fig. 7). Its female flowering during this period was also much earlier than normal, as discussed in its corresponding section. Although atypical, no obvious causes for this behavior were observed, other than the aforementioned higher than average winter temperatures. Mehlenbacher (1991) studied the chilling requirements of 'Gasaway' in Oregon and found that its requirements for catkins and female flowers were between 600-680 and 1040-1170 h, respectively. These requirements are higher than average for hazelnut and do not provide any evidence as to why such early flowering was observed in 201112. The other plants in the study with flowering dates similar to 'Gasaway' (which would be expected to have roughly similar chilling requirements) did not display abnormal flowering behavior during this year. This uncharacteristic year shifted the calculated average enough that the average Stage 1 date of 'Gasaway' was determined to be 28 Feb. Thus, based on its average, 'Gasaway' could be placed into the mid group; however, observations made over a decade at Rutgers University have consistently found it to be one of the latest blooming plants (data not shown). As such, we choose to keep it in the late group.

\section{General trends for catkin development}

Based on the 4-year averages, those accessions placed in the early group began Stage 1 between 23 Jan. and 6 Feb. The mid group began 1 week later, starting on 13 Feb. and concluding on $28 \mathrm{Feb}$. The late group began on 3 Mar. and concluded on 5 Mar. (Table 2). While these averages largely match the order in which the accessions progressed through bloom over each season, they provide only an approximate representation of flowering over the course of the study, as the date of pollen shed and the duration of bloom differed considerable from year-to-year. As an example, in the 2010-11 period, 'Estrella \#1' reached Stage 1 on 18 Feb. (Fig. 6). In the following bloom season (2011-12), it reached Stage 1 on 25 Jan., over 3 weeks earlier than the previous year (Fig. 7). Further, in the 2009-10 period, TdG reached Stage 1 on 21 Jan. However, in the 2010-11 period, TdG reached Stage 1 on 18 Feb., almost 1 month $(28 \mathrm{~d})$ later than the previous year.

Though somewhat disparate, the wide-ranging bloom dates tended to reflect average monthly temperatures. For example, in the 2010-11 period, estimated average monthly temperatures for December, January, and February were $2.4,1.7$, and $0.6{ }^{\circ} \mathrm{C}$ colder than the 4-year averages for those months, respectively (Table 5). Further, the overall mean temperature for the 2010-11 period (average temperature across all days in December, January, and February) was $1.6{ }^{\circ} \mathrm{C}$ colder than the 4 -year average. These colder than average temperatures were clearly reflected in a delay of catkin development until later in the season (Fig. 6). Across all accessions in the 2010-11 period, catkins reached peak bloom (Stage 2 ) on 4 Mar., which is 4 days later than the 4-year average of $28 \mathrm{Feb}$.

Additionally, as temperatures warmed, this delay was followed by a corresponding, tightly compressed window of pollen shed compared with the 
Table 3. Summary of pistillate flower development (Stage 1-4) for 19 hazelnut accessions averaged across 4 years in New Jersey.

\begin{tabular}{|c|c|c|c|c|c|c|c|c|c|}
\hline \multirow[b]{2}{*}{ Group } & \multirow[b]{2}{*}{ Accession } & \multicolumn{2}{|c|}{ Stage 1} & \multicolumn{2}{|c|}{ Stage 2} & \multicolumn{2}{|c|}{ Stage 3} & \multirow{2}{*}{$\frac{\text { Stage } 4}{\text { Date }}$} & \multirow{2}{*}{$\begin{array}{c}\text { Total } \\
\text { duration }(\mathrm{d})\end{array}$} \\
\hline & & Date & Duration $(\mathrm{d})$ & Date & Duration $(\mathrm{d})$ & Date & Duration $(\mathrm{d})$ & & \\
\hline \multirow[t]{2}{*}{ Early } & 'Ratoli' & 24 Dec. & 10 & 3 Jan. & 10 & 13 Jan. & 15 & 28 Jan. & 35 \\
\hline & 'Closca Molla’' & 13 Jan. & 16 & 28 Jan. & 13 & $11 \mathrm{Feb}$. & 14 & 25 Feb. & 43 \\
\hline \multirow[t]{6}{*}{ Mid } & OSU 541.147 & 27 Jan. & 8 & 5 Feb. & 10 & 15 Feb. & 12 & 27 Feb. & 31 \\
\hline & 'Santiam’ & 7 Feb. & 13 & 21 Feb. & 10 & 2 Mar. & 7 & 9 Mar. & 31 \\
\hline & VR 20-11 & 13 Feb. & 7 & $21 \mathrm{Feb}$. & 12 & 4 Mar. & 10 & 13 Mar. & 29 \\
\hline & OSU 526.041 & 14 Feb. & 6 & $20 \mathrm{Feb}$. & 11 & 2 Mar. & 9 & 11 Mar. & 26 \\
\hline & 'Epsilon’' & 15 Feb. & 9 & 23 Feb. & 9 & 3 Mar. & 8 & 11 Mar. & 25 \\
\hline & 'Gamma' & 16 Feb. & 9 & 25 Feb. & 11 & 7 Mar. & 6 & 13 Mar. & 25 \\
\hline \multirow[t]{5}{*}{ Late } & 'Gasaway' & 24 Feb. & 6 & 1 Mar. & 8 & 9 Mar. & 9 & 19 Mar. & 23 \\
\hline & Finland CCOR 187 & 1 Mar. & 7 & 8 Mar. & 6 & 14 Mar. & 3 & 17 Mar. & 16 \\
\hline & OSU 408.040 & 1 Mar. & 5 & 6 Mar. & 9 & 16 Mar. & 5 & 20 Mar. & 19 \\
\hline & OSU 587.044 & 4 Mar. & 6 & 9 Mar. & 6 & 15 Mar. & 5 & 21 Mar. & 17 \\
\hline & NADF \#1 & 5 Mar. & 5 & 9 Mar. & 5 & 14 Mar. & 4 & 19 Mar. & 14 \\
\hline \multirow[t]{4}{*}{ Averages } & Early group avg & 31 Dec. & 14 & 14 Jan. & 12 & 26 Jan. & 15 & 10 Feb. & 41 \\
\hline & Mid group avg & 12 Feb. & 9 & 21 Feb. & 11 & 3 Mar. & 8 & 11 Mar. & 28 \\
\hline & Late group avg & 1 Mar. & 6 & 7 Mar. & 7 & 14 Mar. & 5 & 19 Mar. & 18 \\
\hline & Overall avg & 10 Feb. & 9 & 19 Feb. & 10 & 29 Feb. & 8 & 8 Mar. & 27 \\
\hline
\end{tabular}

4-year average; that is, in the 201011 period, there were $31 \mathrm{~d}$ total from the earliest date of Stage 1 (TdG, 'Ratoli', 'Estrella \#l') to the latest date of Stage 3 ('Gasaway', 408.040), whereas the 4-year average number of days spanning Stage 1 to Stage 3 was 64 (Table 5). One can visualize the impact of this compressed bloom period more clearly when the total cumulative number of pollen shedding days (sum of the total number of days each accession was shedding pollen in a given year; for example, the sum of the total bloom days for Ratoli + total bloom days for TdG + total bloom days for Grand Traverse, etc.) across all 19 accessions for each year is calculated. In the 2010-11 period, only 263 cumulative days of pollen shed were observed, compared with the 4-year cumulative average of $362 \mathrm{~d}$ (Table 5 ). In contrast, the longest window of pollen shed (Stage 1 to Stage 3 was 9l d) was in the 2011-12 period, the warmest year, with 415 cumulative days of pollen shed observed (Table 5 ). These trends fit previous reports of a compressed period of bloom observed in cold regions (Thompson et al., 1996).
The overall earliest period for pollen shed was 2011-12, probably because of the higher than average winter temperatures (Table 5). During this period, four accessions reached Stage l before February, and all accessions but two reached Stage 1 before March. The bloom periods of 2008-09 and 2011-12 had greater variation in the pollen shed dates and durations of most accessions. This appears to follow the varied, inconsistent mean daily temperatures for those respective periods. In winter, inconsistent temperatures usually translate to periodic warm spells. If the temperatures are frequently warming and cooling, some plants may respond quickly to these fluctuations, causing variation in the pollen shed periods. By contrast, in cold stable winters, plants seem to stay dormant until consistently warmer temperatures arrive, whereas in warm stable winters, plants are active and flower earlier. Less stable winter temperatures appear to result in more starting-and-stopping of flower development and seemingly lead to more varied windows of pollen dispersal.
In terms of male flower bloom of all accessions over all 4 years, the average date for Stage 1 was $21 \mathrm{Feb}$. with peak pollen shed (Stage 2 ) beginning 28 Feb. Stage 3 was reached on 13 Mar. The latest average period for these stages for all accessions was 2009-10, which reached Stages 1 through 3 six, six, and eight days later than the 4-year average, respectively. The earliest average period of bloom was 2011-12, with the three stages of pollen shed reaching 13,13 , and 11 $\mathrm{d}$ earlier than the 4-year average.

\section{Female flower development (pistillate bloom)}

EARLY GROUP. The earliest plants to reach Stage 1 of female flowering were 'Ratoli', TdG, and 'Closca Molla'. These three cultivars consistently bloomed in this order, except for in the 2008-09 period, when TdG bloomed $1 \mathrm{~d}(26 \mathrm{Dec}$.) earlier than Ratoli (27 Dec.) (Table 3, Fig. 3). This date was 2 weeks earlier than the 4-year average bloom date of the next earliest blooming accession (OSU 541.147, Jan. 27), which, similar to the male flower groups, was chosen to be the earliest blooming accession 
Table 4. Summary of vegetative bud development (Stage 1-3) for 19 hazelnut accessions averaged across 4 years in New Jersey. Stage 1 represents the first sign of a leaf tip emerging from a swollen bud. Stage 2 occurs when the leaf is mostly out of the bud. Stage 3 occurs when the true leaves have fully emerged from the bud.

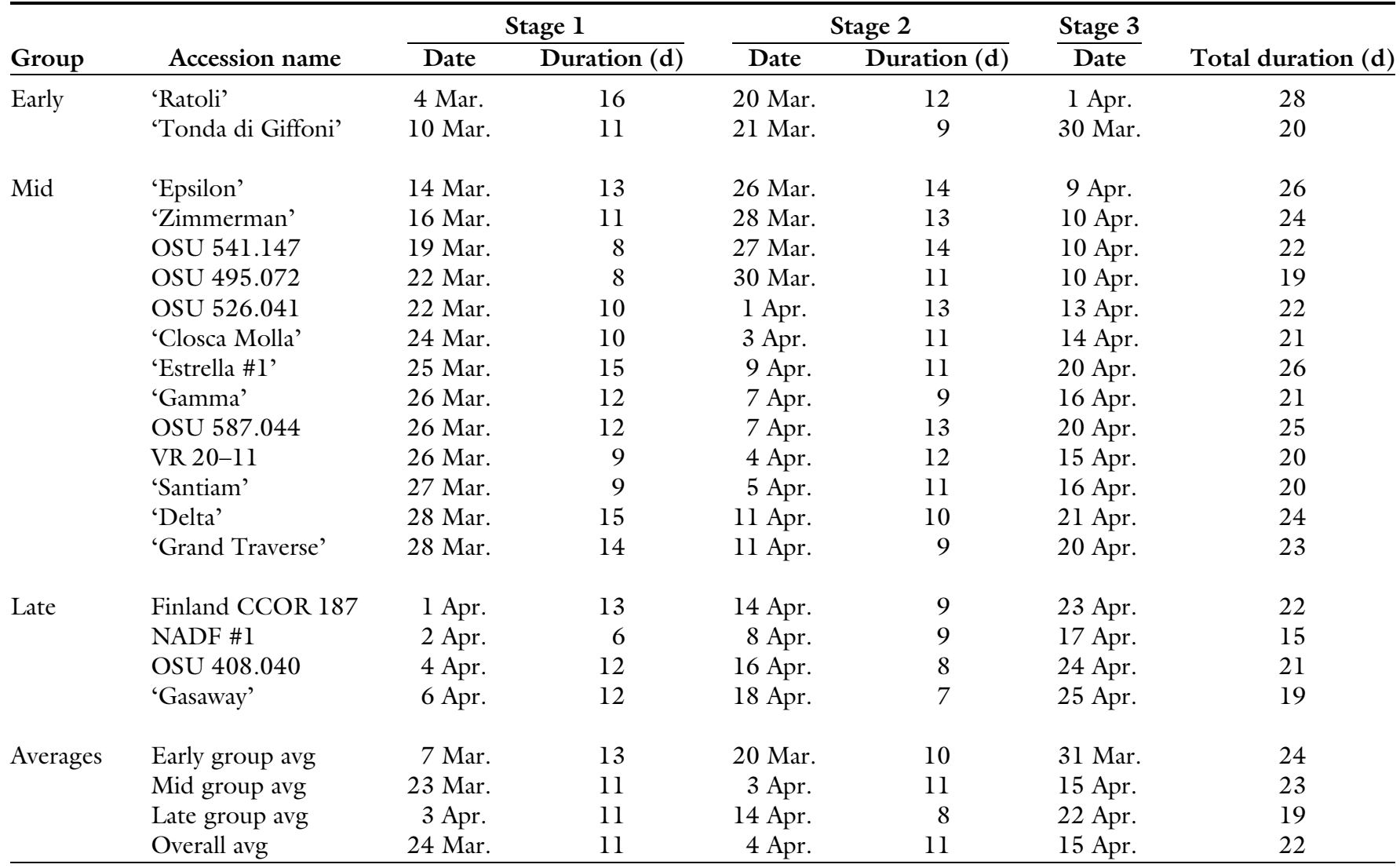

Table 5. Monthly weather summary and bloom period for staminate and pistillate flowers of hazelnut accessions.

\begin{tabular}{|c|c|c|c|c|c|c|c|c|c|}
\hline \multirow[b]{2}{*}{ Bloom period } & \multicolumn{5}{|c|}{ Monthly avg $\left({ }^{\circ} \mathrm{C}\right)^{\mathrm{z}}$} & \multicolumn{2}{|c|}{ Length of bloom period $(d)^{y}$} & \multicolumn{2}{|c|}{ Cumulative bloom period (d) } \\
\hline & Dec. & Jan. & Feb. & Mar. & Apr. & Staminate & Pistillate & Staminate & Pistillate \\
\hline $2008-09$ & 2.4 & -2.9 & 1.3 & 4.7 & 8.5 & 74 & 101 & 450 & 571 \\
\hline $2010-11$ & -0.3 & -2.8 & 0.7 & 5.3 & 10.0 & 31 & 95 & 263 & 471 \\
\hline $2011-12$ & 4.8 & 1.5 & 3.6 & 9.6 & 9.9 & 91 & 98 & 415 & 572 \\
\hline 4-year avg & 2.1 & -1.1 & 1.3 & 6.8 & 11.0 & 64 & 96 & 362 & 521 \\
\hline
\end{tabular}

${ }^{\mathrm{z}}\left(1.8 \times{ }^{\circ} \mathrm{C}\right)+32={ }^{\circ} \mathrm{F}$

y Length of bloom period represents the number of days between the first accession to reach Stage 1 and the last accession to reach Stage 3 (staminate) or Stage 4 (pistillate). ${ }^{x}$ Cumulative bloom period represents the total number of days each accession bloomed [number of days between Stage 1 and Stage 3 (staminate) or Stage 4 (pistillate)] added together for a given year.

placed in the female flower mid group, to be discussed subsequently. The earliest incidence of female bloom was in the 2011-12 period, when both TdG and 'Ratoli' began Stage 1 on 20 Dec. (Fig. 7), which directly reflects the warm temperatures recorded that month $\left(4.8{ }^{\circ} \mathrm{C}\right.$ average, reaching daily averages as high as $15.6^{\circ} \mathrm{C}$ on $7 \mathrm{Dec}$. and $11.4^{\circ} \mathrm{C}$ on 22-23 Dec.) (Table 5). The latest incidences of female bloom by a plant in this early group were in the 200809 and 2010-11 periods, when 'Closca Molla' reached Stage 1 on 16 Jan. in both years. In Oregon, chilling requirements for female flowers of TdG were estimated to be between 600$680 \mathrm{~h}$, placing it among the lowest of all plants evaluated. TdG reached Stage 1 in Oregon on 13 Nov. and displayed fully exserted stigmas (Stage 3 ) on 18 Dec. (Mehlenbacher, 1991). These dates are significantly earlier than those observed in New Jersey (Stage 1 on 25 Dec. and Stage 3 on 23 Jan., based on 4-year average) and provide a clear indication of how flowering behavior differs between the two regions.
Mid Group. Following the three earliest accessions in female bloom were OSU 541.147, 'Zimmerman', 'Delta', 'Santiam', VR 20-11, OSU 526.041, 'Epsilon', 'Gamma', OSU 495.072, 'Grand Traverse', and 'Estrella \#l'. These plants generally bloomed in the order presented, consistently $2-3$ weeks after those discussed in the early group (Table 3 ). Typically, there was a span of about 1 month separating the earliest of this group (OSU 541.147) and latest ('Estrella \#l'). The earliest start of female flowering for any accession in 
this group was 20 Jan. 2012 by 'Santiam'. The latest accessions to begin Stage 1 during any year were 'Grand Traverse' and 'Estrella \#l', on 3 Mar. 2009. Any outliers from this group are discussed in the early and late group sections.

LATE Group. The remaining group of accessions includes 'Gasaway', Finland CCOR 187, OSU 408.040, OSU 587.044, and NADF \#1. These plants typically began Stage 1 around the beginning of March, with the exception of 'Gasaway', whose anomalous year is described in the preceding section. Excepting 'Gasaway', $\approx 1$ week separates the average bloom date of the earliest plant from this group (Finland CCOR 187, 4year average date 1 Mar.) from the latest plant included in the mid group ('Estrella \#l') (Table 3). Disregarding 'Gasaway' in 2012, the earliest date for reaching Stage 1 was 18 Feb. 2011 by Finland CCOR 187. This early date is reflected in the very high February temperatures reaching up to $12.2^{\circ} \mathrm{C}$ during the week of evaluations (in February, 4-year average temperature is $1.3^{\circ} \mathrm{C}$ ). The latest observation of female flowers reaching Stage 1 was on 8 Mar. 2009 by NADF \#1. Temperatures the week leading up to this date dipped as low as $-8.1^{\circ} \mathrm{C}$, whereas the temperature on 8 Mar. reached $13.1^{\circ} \mathrm{C}$. The $2008-09$ bloom period featured a consistently cold winter followed by fluctuating temperatures in February and March (Table 5).

\section{General trends for female flower development}

Based on the 4-year averages, the accessions placed in the early group reached Stage 1 between $24 \mathrm{Dec}$. and 13 Jan. Accessions placed in the mid group reached Stage 1 ranging from 27 Jan. to 25 Feb., whereas those in late group spanned from 1 Mar. to 5 Mar. Our placement of the accessions in these groups for the female flowers reflected those for male flower groups, with only minor differences. For both flower types, the early group holds three accessions, including TdG and 'Ratoli' in both. 'Closca Molla' was included in the early group for female flowers, whereas 'Estrella \#l' was included in the early group for male flowers. For the late group, both also held the same number of accessions with four in common ('Gasaway', OSU 408.040, OSU 587.044, and
Finland CCOR 187). However, NADF \#l was the fifth member for the female flowers, whereas 'Epsilon' was included in the late group for the male flowers.

In terms of female flower development of all the accessions averaged over all 4 years, Stage 1 was reached on 13 Feb., followed by 19 Feb. for Stage 2, 29 Feb./1 Mar. for Stage 3, and 8 Mar. for Stage 4. The 2008-09 period had the latest average female bloom, reaching Stages 1 through 4 three, five, five, and seven days later than their 4-year averages, respectively. In contrast, the 2011-12 period was considerably earlier than the 4-year average, reaching Stages 1 through 4 eight, nine, seven, and five days earlier, respectively. As the $2011-$ 12 period was significantly warmer than the other years, this was not unexpected. However, by monthly average, 2008-09 was not the overall coldest period (2010-11 was), although it did have the coldest January $\left(-2.9^{\circ} \mathrm{C}\right.$, compared with an average of $\left.-1.1^{\circ} \mathrm{C}\right)$ and March $\left(4.7^{\circ} \mathrm{C}\right.$, compared with an average of $6.8^{\circ} \mathrm{C}$ ) (Table 5), which likely corresponds to why it had the latest flowering dates.

Vegetative BUd BReak. The dates of vegetative budbreak for all accessions were loosely similar to the groupings for pollen shed and female flowering. 'Ratoli' and TdG were again the two earliest. 'Ratoli' and TdG broke bud dormancy considerably earlier than the other accessions, averaging 4 Mar. and 10 Mar., respectively, across all 4 years (Table 4 ). In the 2008-09 period, 'Ratoli' began budbreak on $18 \mathrm{Feb}$., the earliest date recorded across the study. In contrast, in the 2010-11 period, both 'Ratoli' and TdG did not begin budbreak until 17 Mar., the latest date recorded for these plants. This trend was reflected across nearly all accessions by later than average budbreak dates that year (Fig. 6).

'Gasaway' had the consistently latest budbreak dates, followed by OSU 408.040, NADF \#1, and Finland CCOR 187. These four accessions each averaged budbreak dates starting in April. All of the other accessions typically began budbreak between 14 and 29 Mar., leading them to be classified as our mid-group accessions (Table 4). The latest date a plant began vegetative budbreak was on 13 Apr. 2011 by 'Gasaway'. This year had by far the latest budbreak for all accessions, with only five breaking dormancy in March, which is reflected in the colder than average monthly temperatures. The earliest breaking of bud dormancy by one of the four latest budbreak plants was on 18 Mar. 2010 by Finland CCOR 187, which is reflected in the fact that the 200910 period had the earliest average budbreak across all accessions.

For vegetative budbreak averaged over all 4 years, the early group accessions broke dormancy on 4 Mar. and 10 Mar., respectively. The mid group began on 14 Mar. and ended on 28 Mar. Plants in the late group ranged from 1 Apr. to 6 Apr. The average date of vegetative budbreak across all of the accessions over the 4 years occurred on 24 Mar.

\section{Conclusions}

This study was intended to provide a systematic, multiyear record of flower and vegetative budbreak phenology of hazelnut in central New Jersey. Our results showed that the accessions followed a similar progression of bloom each year for both staminate and pistillate flowers, which allowed their placement into early-, mid-, and late-flowering groups. Despite one or two minor exceptions, these groups stayed consistent each year. However, the date and duration of bloom differed each year, which largely corresponded to average air temperature trends. In colder than average years, bloom was delayed until later in the winter, which then led to a compressed period of flowering once temperatures warmed, as reported from other colder regions (Črepinšek et al., 2012; Germain, 1994; Piskornik et al., 2001; Solar and Stampar, 2009). In contrast, relatively warm temperatures over the bloom period led to earlier flowering as well as a significant lengthening of the duration of bloom, similar to responses reported in Mediterranean climates (Mehlenbacher, 1991; Thompson et al., 1996).

Olsen et al. (2000) states that $90 \%$ of cultivars evaluated in Oregon are protandrous. In contrast, our results show that most of the accessions examined in our study, across all years, were protogynous. Aside from 'Estrella \#1', 'NADF \#1', and 'Grand Traverse', which were consistently protandrous, the rest of the accessions were protogynous averaged across all 
years, with some minor year-to-year exceptions. These observations support the hypothesis of Thompson et al. (1996) and others in that protogyny is more common in regions with colder winters. However, our flowering windows were not as compressed as previously reported for cold region in most years (Crepinšek et al., 2012; Germain, 1994), possibly reflected by the fact that our climate is relatively mild [considered to be between zone $6 \mathrm{~B}$ and 7A (USDA, 2013)] and is somewhat moderated by its proximity to the Atlantic Ocean, which is about $40 \mathrm{~km}$ away.

A thorough study on the cold hardiness of catkins across a wider collection of germplasm should be conducted in the future. Over the course of this study, only minor catkin injury was observed in 1 year (2011-12 period) and was not included as a component of this research. However, the 4-year span of our study does not represent the temperature extremes possible in the eastern United States, where catkin damage is a more likely possibility over a longer period, as described by Slate (1933) and MacDaniels (1964).

For current and prospective growers, our results provide both direct information on a number of available EFB-resistant cultivars and breeding selections and an overview of how flower and budbreak phenology may respond to temperature fluctuations in our region. These results should aid growers in choosing appropriate plants (pollenizers and nut producers) for production in central New Jersey and other places with similar climates. Our results also present useful data to support selection of breeding parents for developing new cultivars adapted to this region and as a foundation for further flowering research.

\section{Literature cited}

Beyhan, N. and D. Marangoz. 2007. An investigation of the relationship between reproductive growth and yield loss in hazelnut. Scientia Hort. 113:208-215.

Cameron, H.R. 1976. Eastern filbert blight established in the Pacific Northwest. Plant Dis. Rptr. 60:737-740.

Capik, J.M. and T.J. Molnar. 2012. Assessment of host (Corylus sp.) resistance to eastern filbert blight in New Jersey. J. Amer. Soc. Hort. Sci. 137:157-172.
Capik, J.M., M. Muehlbauer, A. Novy, J.M. Honig, and T.J. Molnar. 2013. Eastern filbert blight resistant hazelnuts from Russia, Ukraine, and Poland. HortScience 48:466-473.

Chen, H., S.A. Mehlenbacher, and D.C. Smith. 2007. Hazelnut accessions provide new sources of resistance to eastern filbert blight. HortScience 42:466-469.

Črepinšek, Z., F. Šstampar, L. Kajfež Bogataj, and A. Solar. 2012. The response of Corylus avellana L. phenology to rising temperature in north-eastern Slovenia. Intl. J. Biometeorol. 56:681-694.

Davison, A.D. and R.M. Davidson. 1973. Apioporthe and Monochaetia canker reported in western Washington. Plant Dis. Rptr. 57:522-523.

Food and Agriculture Organization of the United Nations. 2013. Agricultural production, crops primary. 8 Oct. 2013. $<$ http://faostat.fao.org/site/567/default. aspx\#ancor $>$.

Fuller, A.S. 1908. The nut culturist. Orange Judd, New York, NY.

Germain, E. 1994. The reproduction of hazelnut (Corylus avellana L.): A review. Acta Hort. 351:195-210.

Germain, E. and J.P. Sarraquigne. 2004. Le noisetier (in French). Alinéa, Paris, France.

Hummer, K., H.B. Lagerstedt, and S.K. Kim. 1986. Filbert acclimation, maximum cold hardiness, and deacclimation. J. Amer. Soc. Hort. Sci. 111:474-482.

Johnson, K.B., S.A. Mehlenbacher, J.K. Stone, and J.W. Pscheidt. 1996. Eastern filbert blight of european hazelnut: It's becoming a manageable disease. Plant Dis. 80:1308-1316.

Johnson, K.B. and J.N. Pinkerton. 2002. Eastern filbert blight, p. 44-46. In: B.L. Teviotdale, T.J. Michailides, and J.W. Pscheidt (eds.). Compendium of nut crop diseases in temperate zones. APS Press, St. Paul, MN.

Julian, J., C. Seavert, and J.L. Olsen. 2009. An economic evaluation of the impact of eastern filbert blight resistant cultivars in Oregon, U.S.A. Acta Hort. $845: 725-732$.

Lunde, C.F., S.A. Mehlenbacher, and D.C. Smith. 2000. Survey of hazelnut cultivars for response to eastern filbert blight inoculation. HortScience 35:729-731.

MacDaniels, L.H. 1964. Hazelnuts and filberts. Horticulture 42:44-45, 53.

Mehlenbacher, S.A. 1991. Chilling requirements of hazelnut cultivars. Scientia Hort. 47:271-282.
Mehlenbacher, S.A. 1994. Genetic improvement of the hazelnut. Acta Hort. 351:551-557.

Mehlenbacher, S.A. 1997. Revised dominance hierarchy for $S$-alleles in Corylus avellana L. Theor. Appl. Genet. 94:360366.

Mehlenbacher, S.A. and J. Olsen. 1997. The hazelnut industry in Oregon. Acta Hort. 445:337-345.

Mehlenbacher, S.A. and D.C. Smith. 2004. Hazelnut pollenizers 'Gamma', 'Delta', 'Epsilon', and 'Zeta'. HortScience 39:1498-1499.

Mehlenbacher, S.A., D.C. Smith, and R.L. McCluskey. 2009. 'Yamhill' hazelnut. HortScience 44:845-847.

Mehlenbacher, S.A., D.C. Smith, and R. McCluskey. 2011. 'Jefferson' hazelnut. HortScience 46:662-664.

Mehlenbacher, S.A., D.C. Smith, and R. McCluskey. 2012. 'Eta' and 'Theta' hazelnut pollenizers. HortScience 47: 1180-1181.

Mehlenbacher, S.A., D.C. Smith, and R.L. McCluskey. 2013. 'Dorris' hazelnut. HortScience 48:796-799.

Mehlenbacher, S.A. and M.M. Thompson. 1988. Dominance relationships among $\mathrm{S}$-alleles in Corylus avellana L. Theor. Appl. Genet. 76:669-672.

Mehlenbacher, S.A. and M.M. Thompson. 1991. Four hazelnut pollenizers resistant to eastern filbert blight. HortScience 26: $442-443$.

Mehlenbacher, S.A., M.M. Thompson, and H.R. Cameron. 1991. Occurrence and inheritance of immunity to eastern filbert blight in 'Gasaway' hazelnut. HortScience 26:410-411.

Molnar, T.J., J.M. Capik, and J.C. Goffreda. 2009. Response of hazelnut progenies from known resistant parents to Anisogramma anomala in New Jersey, U.S.A. Acta Hort. 845:73-81.

Molnar, T.J., J.C. Goffreda, and C.R. Funk. 2010. Survey of Corylus resistance to Anisogramma anomala from different geographic locations. HortScience 45: $832-836$

National Climate Data Center. 2013. Record of climatological observations, Dec. 2008-April 2012, New Brunswick Station. 29 July 2013. <http://www.ncdc. noaa.gov>.

Olsen, J., S.A. Mehlenbacher, and A.N. Azarenko. 2000. Hazelnut pollination. HortTechnology 10:113-115.

Pinkerton, J.N., K.B. Johnson, S.A. Mehlenbacher, and J.W. Pscheidt. 1993. 


\section{Research Reports}

Susceptibility of european hazelnut clones to eastern filbert blight. Plant Dis. 77:261266.

Piskornik, Z., G.M. Wyzgolik, and M. Piskornik. 2001. Flowering of hazelnut cultivars from different regions under the climatic conditions of southern Poland. Acta Hort. 556:529-536.

Reed, C.A. and J. Davidson. 1958. The improved nut trees of North America. Devin-Adair, New York, NY.
Sathuvalli, V., S.A. Mehlenbacher, and D.C. Smith. 2010. Response of hazelnut accessions to greenhouse inoculation with Anisogramma anomala. HortScience 45: 1116-1119.

Slate, G.L. 1933. Notes on the filbert orchard at Geneva. Annu. Rpt. Northern Nut Growers Assn. 24:34-37.

Solar, A. and F. Stampar. 2009. Performance of hazelnut cultivars from Oregon in northeastern Slovenia. HortTechnology 19:653-659.
Thompson, M.M. 1979. Genetics of incompatibility in Corylus avellana L. Theor. Appl. Genet. 54:113-116.

Thompson, M.M., H.B. Lagerstedt, and S.A. Mehlenbacher. 1996. Hazelnuts, p. 125-184. In: J. Janick and J.N. Moore (eds.). Fruit breeding, Vol. 3. Nuts. Wiley, New York, NY.

U.S. Department of Agriculture. 2013. USDA plant hardiness zone map. 27 Nov. 2013. <http://planthardiness.ars.usda. gov/PHZMWeb/\#>. 
Supplemental Table 1. Pistillate, staminate, and vegetative bloom dates for 19 accessions of hazelnut in New Jersey.

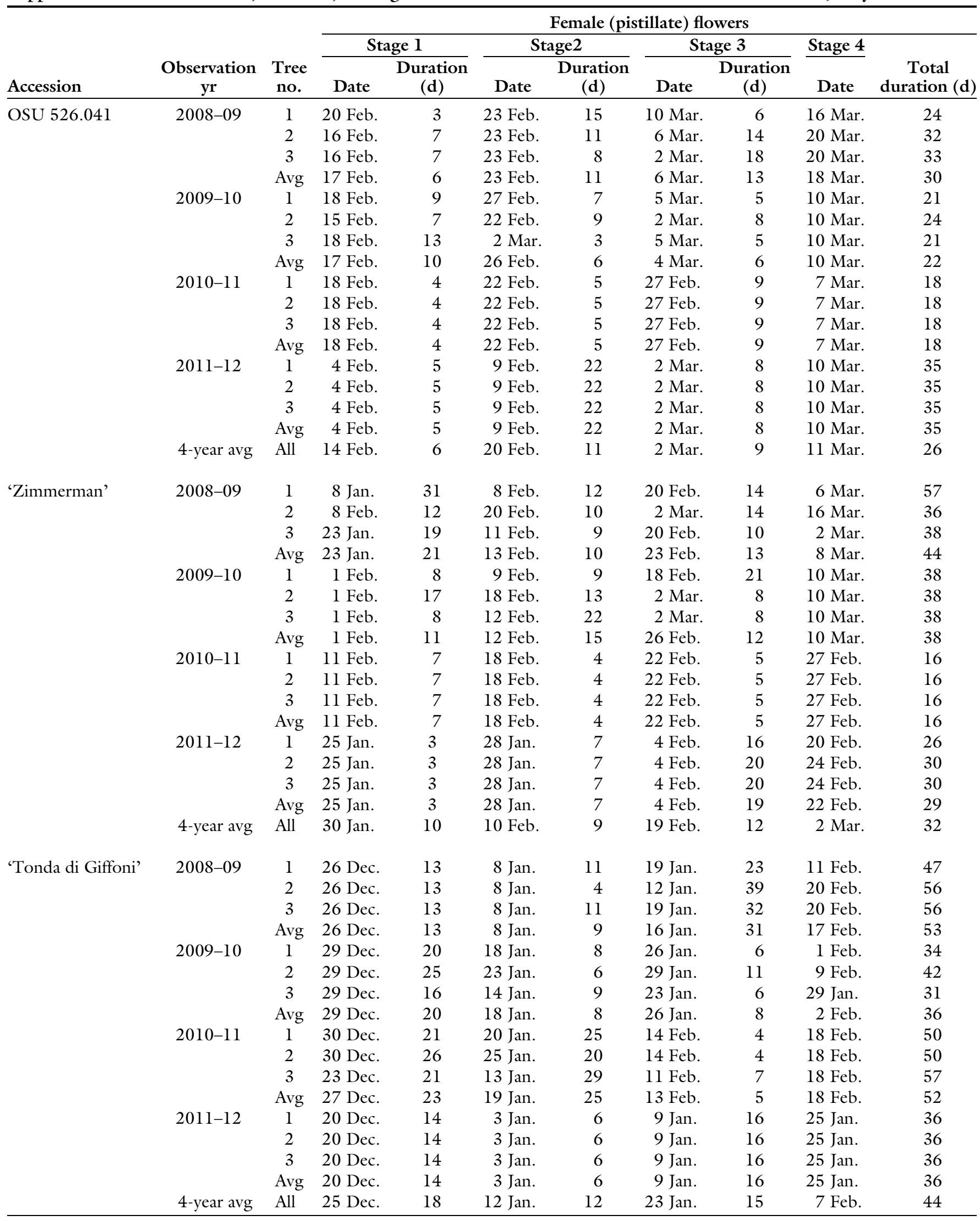


Supplemental Table 1. (Continued) Pistillate, staminate, and vegetative bloom dates for 19 accessions of hazelnut in New Jersey.

\begin{tabular}{|c|c|c|c|c|c|c|c|c|c|c|}
\hline \multirow[b]{3}{*}{ Accession } & \multirow[b]{3}{*}{$\begin{array}{c}\text { Observation } \\
\mathrm{yr}\end{array}$} & \multirow[b]{3}{*}{$\begin{array}{l}\text { Tree } \\
\text { no. }\end{array}$} & \multicolumn{8}{|c|}{ Female (pistillate) flowers } \\
\hline & & & \multicolumn{2}{|c|}{ Stage 1} & \multicolumn{2}{|c|}{ Stage2 } & \multicolumn{2}{|c|}{ Stage 3} & \multirow{2}{*}{$\begin{array}{c}\text { Stage } 4 \\
\text { Date }\end{array}$} & \multirow[b]{2}{*}{$\begin{array}{c}\text { Total } \\
\text { duration }(\mathrm{d})\end{array}$} \\
\hline & & & Date & $\begin{array}{c}\text { Duration } \\
\text { (d) }\end{array}$ & Date & $\begin{array}{c}\text { Duration } \\
\text { (d) }\end{array}$ & Date & $\begin{array}{c}\text { Duration } \\
\text { (d) }\end{array}$ & & \\
\hline \multirow[t]{12}{*}{ VR 20-11 } & \multirow[t]{3}{*}{$2008-09$} & 1 & 16 Feb. & 7 & 23 Feb. & 25 & 20 Mar. & 7 & 27 Mar. & 39 \\
\hline & & 2 & 20 Feb. & 10 & 2 Mar. & 25 & 27 Mar. & 4 & 31 Mar. & 39 \\
\hline & & 3 & 11 Feb. & 19 & 2 Mar. & 18 & 20 Mar. & 7 & 27 Mar. & 44 \\
\hline & \multirow{3}{*}{$2009-10$} & 2 & 22 Feb. & 5 & 27 Feb. & 7 & 5 Mar. & 5 & 10 Mar. & 17 \\
\hline & & 3 & 22 Feb. & 9 & 2 Mar. & 3 & 5 Mar. & 5 & 10 Mar. & 17 \\
\hline & & Avg & 22 Feb. & 6 & 28 Feb. & 6 & 5 Mar. & 5 & 10 Mar. & 17 \\
\hline & \multirow[t]{3}{*}{$2010-11$} & 1 & 18 Feb. & 4 & 22 Feb. & 5 & 27 Feb. & 12 & 10 Mar. & 21 \\
\hline & & 2 & 18 Feb. & 4 & 22 Feb. & 10 & 3 Mar. & 7 & 10 Mar. & 21 \\
\hline & & 3 & 18 Feb. & 4 & 22 Feb. & 10 & 3 Mar. & 7 & 10 Mar. & 21 \\
\hline & \multirow{2}{*}{$2011-12$} & 3 & 31 Jan. & 4 & 4 Feb. & 9 & 13 Feb. & 22 & 6 Mar. & 35 \\
\hline & & Avg & 30 Jan. & 7 & 5 Feb. & 11 & 16 Feb. & 18 & 6 Mar. & 36 \\
\hline & 4-year avg & All & 13 Feb. & 7 & $21 \mathrm{Feb}$ & 12 & 4 Mar. & 10 & 13 Mar. & 29 \\
\hline \multirow[t]{10}{*}{ 'Gasaway' } & \multirow[t]{4}{*}{ 2008-09 } & 1 & 6 Mar. & 4 & 10 Mar. & 17 & 27 Mar. & 4 & 31 Mar. & 25 \\
\hline & & 2 & 2 Mar. & 14 & 16 Mar. & 8 & 24 Mar. & 7 & 31 Mar. & 29 \\
\hline & & 3 & 2 Mar. & 8 & 10 Mar. & 10 & 20 Mar. & 11 & 31 Mar. & 29 \\
\hline & & Avg & 3 Mar. & 9 & 12 Mar. & 12 & 23 Mar. & 7 & 31 Mar. & 28 \\
\hline & \multirow[t]{4}{*}{ 2009-10 } & 1 & 2 Mar. & 8 & 10 Mar. & 6 & 16 Mar. & 4 & 20 Mar. & 18 \\
\hline & & 2 & 5 Mar. & 5 & 10 Mar. & 6 & 16 Mar. & 4 & 20 Mar. & 15 \\
\hline & & 3 & 5 Mar. & 5 & 10 Mar. & 6 & 16 Mar. & 4 & 20 Mar. & 15 \\
\hline & & Avg & 4 Mar. & 6 & 10 Mar. & 6 & 16 Mar. & 4 & 20 Mar. & 16 \\
\hline & & Avg & 30 Jan. & 7 & 5 Feb. & 11 & 16 Feb. & 18 & 6 Mar. & 36 \\
\hline & 4-year avg & All & 24 Feb. & 6 & 1 Mar. & 8 & 9 Mar. & 9 & 19 Mar. & 23 \\
\hline 'Grand Traverse' & 2008-09 & 1 & 6 Mar. & 4 & 10 Mar. & 6 & 16 Mar. & 4 & 20 Mar. & 14 \\
\hline & & 2 & 2 Mar. & 4 & 6 Mar. & 10 & 16 Mar. & 8 & 24 Mar. & 22 \\
\hline & & 3 & 2 Mar. & 8 & 10 Mar. & 6 & 16 Mar. & 8 & 24 Mar. & 22 \\
\hline & & Avg & 3 Mar. & 5 & 8 Mar. & 7 & 16 Mar. & 7 & 22 Mar. & 19 \\
\hline & $2009-10$ & 1 & 2 Mar. & 3 & 5 Mar. & 5 & 10 Mar. & 6 & 16 Mar. & 14 \\
\hline & & 2 & 2 Mar. & 3 & 5 Mar. & 5 & 10 Mar. & 6 & 16 Mar. & 14 \\
\hline & & 3 & 2 Mar. & 3 & 5 Mar. & 5 & 10 Mar. & 6 & 16 Mar. & 14 \\
\hline & & Avg & 2 Mar. & 3 & 5 Mar. & 5 & 10 Mar. & 6 & 16 Mar. & 14 \\
\hline & $2010-11$ & 1 & 18 Feb. & 9 & 27 Feb. & 12 & 10 Mar. & 7 & 17 Mar. & 28 \\
\hline & & 2 & 27 Feb. & 5 & 3 Mar. & 7 & 10 Mar. & 7 & 17 Mar. & 19 \\
\hline & & 3 & 18 Feb. & 14 & 3 Mar. & 7 & 10 Mar. & 7 & 17 Mar. & 28 \\
\hline & & Avg & 21 Feb. & 9 & 1 Mar. & 9 & 10 Mar. & 7 & 17 Mar. & 25 \\
\hline & $2011-12$ & 1 & 17 Feb. & 7 & 24 Feb. & 11 & 6 Mar. & 14 & 20 Mar. & 32 \\
\hline & & 2 & 13 Feb. & 7 & 20 Feb. & 15 & 6 Mar. & 14 & 20 Mar. & 36 \\
\hline & & 3 & 13 Feb. & 7 & 20 Feb. & 15 & 6 Mar. & 14 & 20 Mar. & 36 \\
\hline & & Avg & 14 Feb. & 7 & 21 Feb. & 14 & 6 Mar. & 14 & 20 Mar. & 35 \\
\hline & 4-year avg & All & 24 Feb. & 6 & 1 Mar. & 9 & 10 Mar. & 8 & 18 Mar. & 23 \\
\hline
\end{tabular}


Supplemental Table 1. (Continued) Pistillate, staminate, and vegetative bloom dates for 19 accessions of hazelnut in New Jersey.

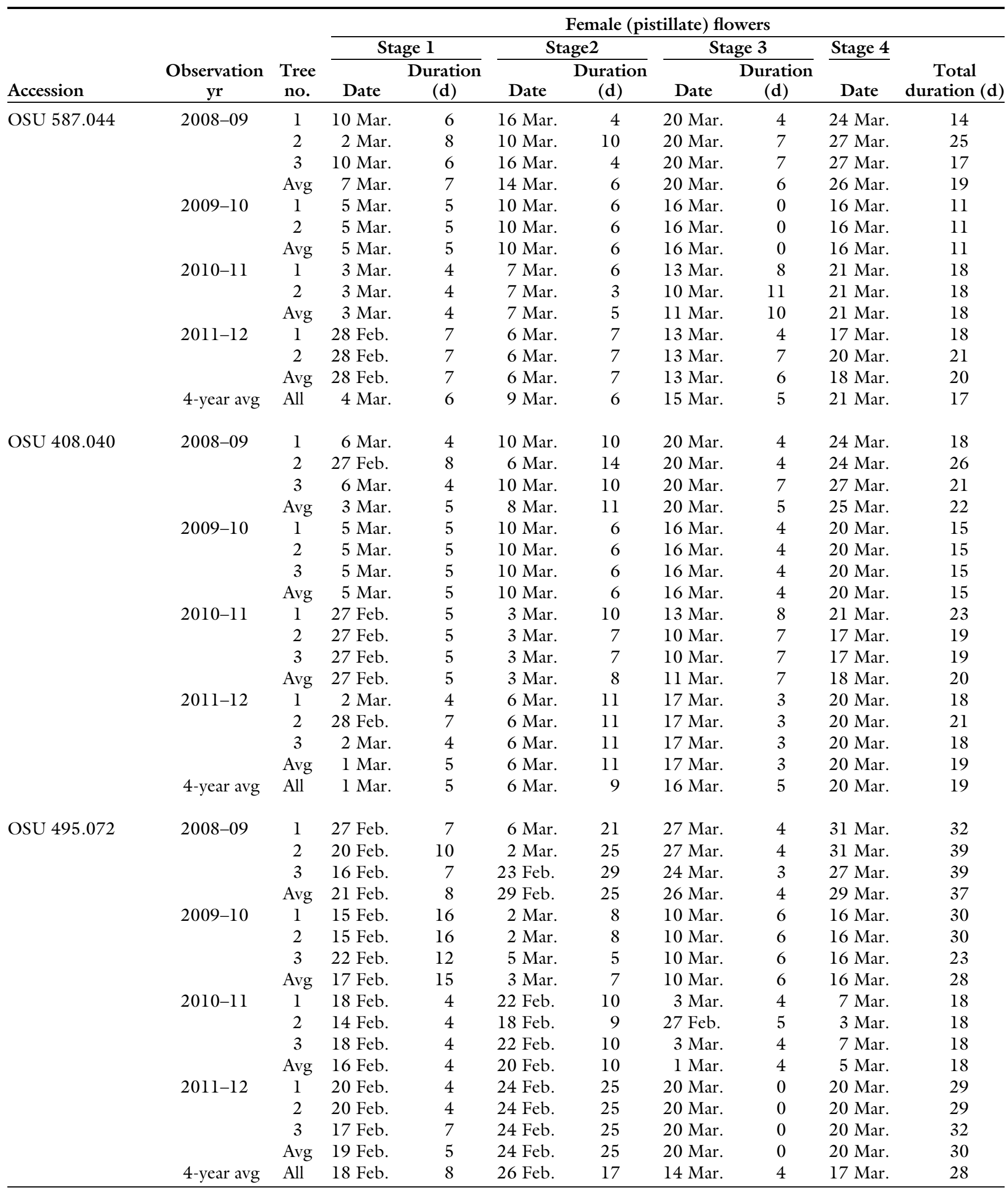

(Continued on next page) 
Supplemental Table 1. (Continued) Pistillate, staminate, and vegetative bloom dates for 19 accessions of hazelnut in New Jersey.

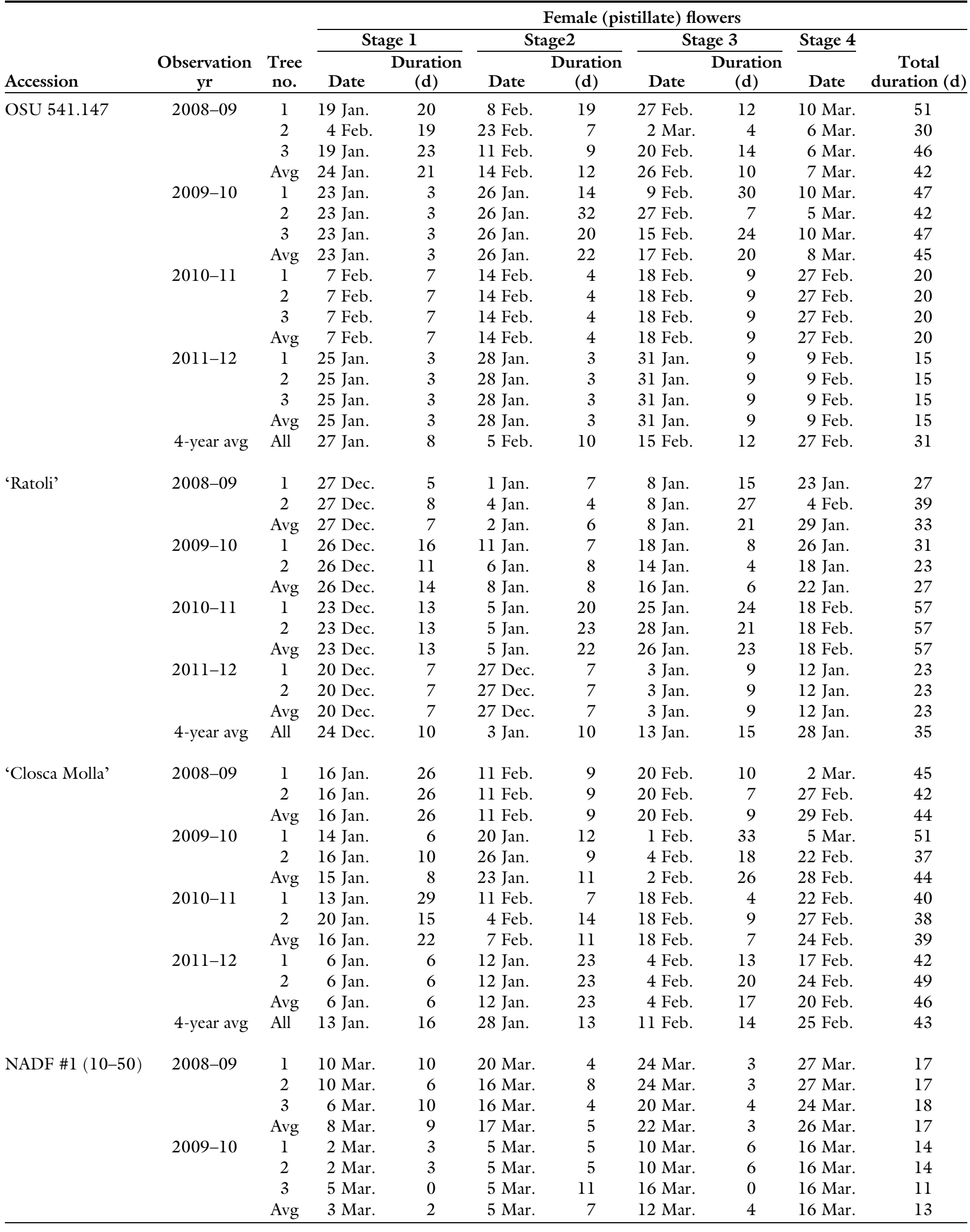


Supplemental Table 1. (Continued) Pistillate, staminate, and vegetative bloom dates for 19 accessions of hazelnut in New Jersey.

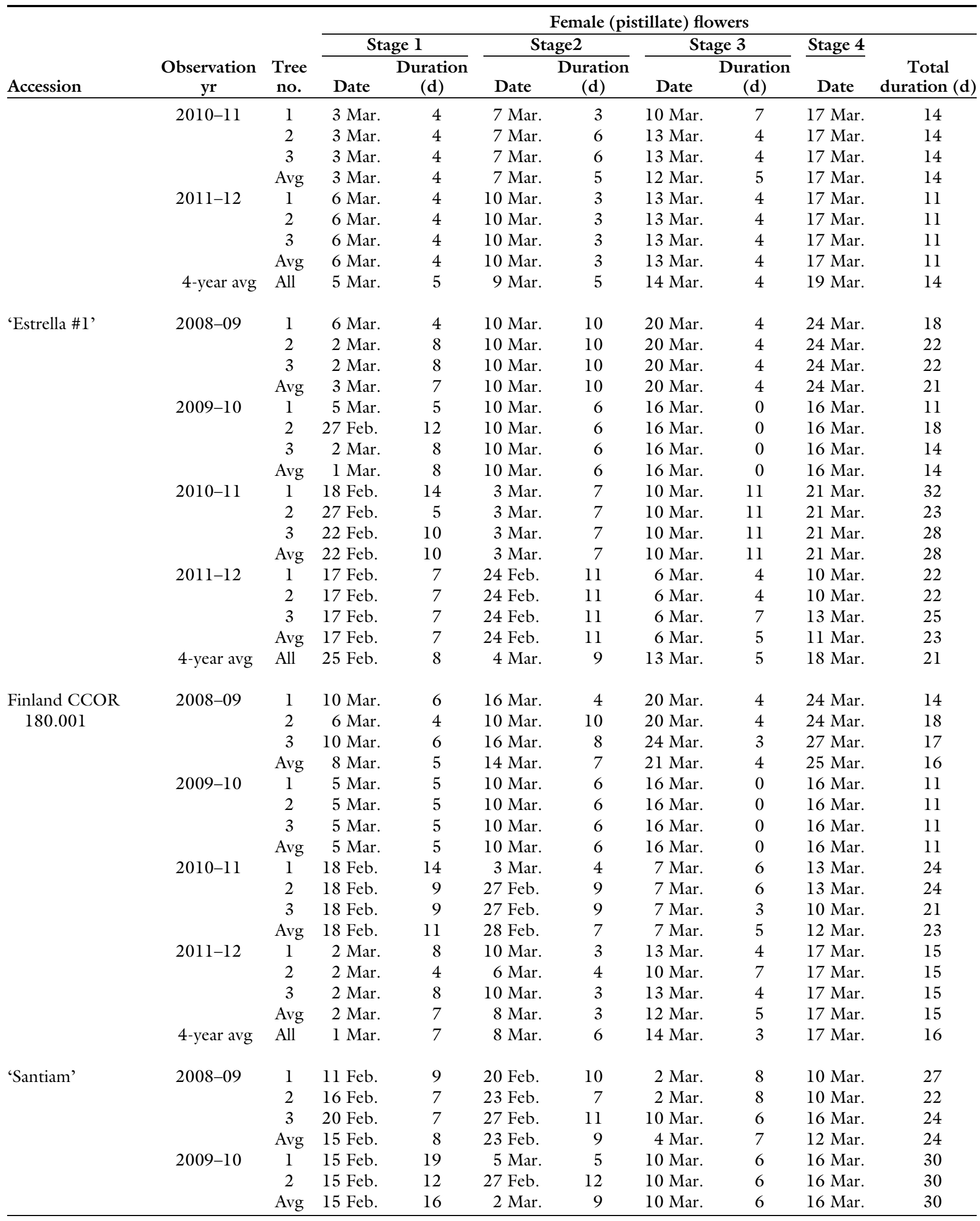


Supplemental Table 1. (Continued) Pistillate, staminate, and vegetative bloom dates for 19 accessions of hazelnut in New Jersey.

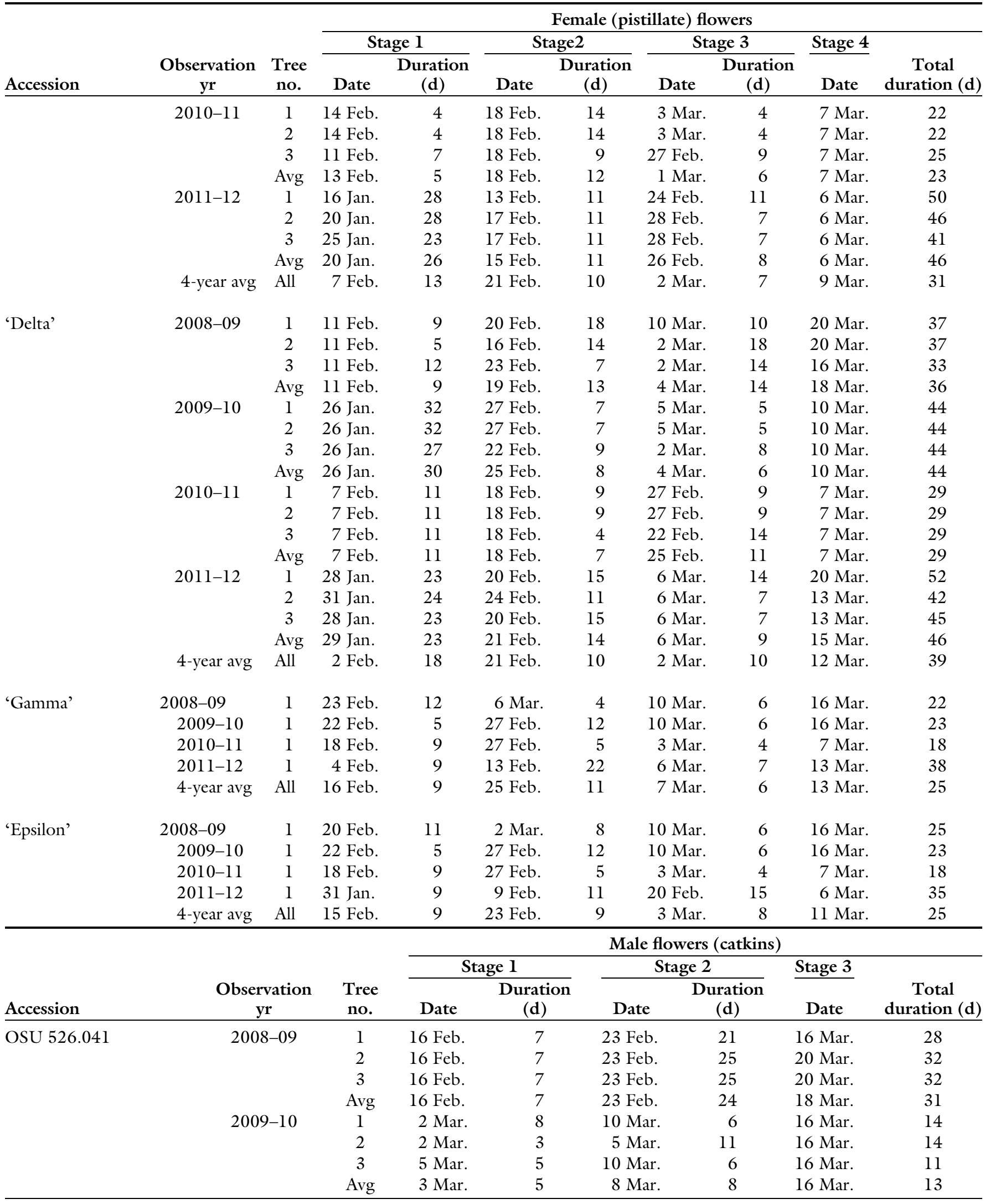


Supplemental Table 1. (Continued) Pistillate, staminate, and vegetative bloom dates for 19 accessions of hazelnut in New Jersey.

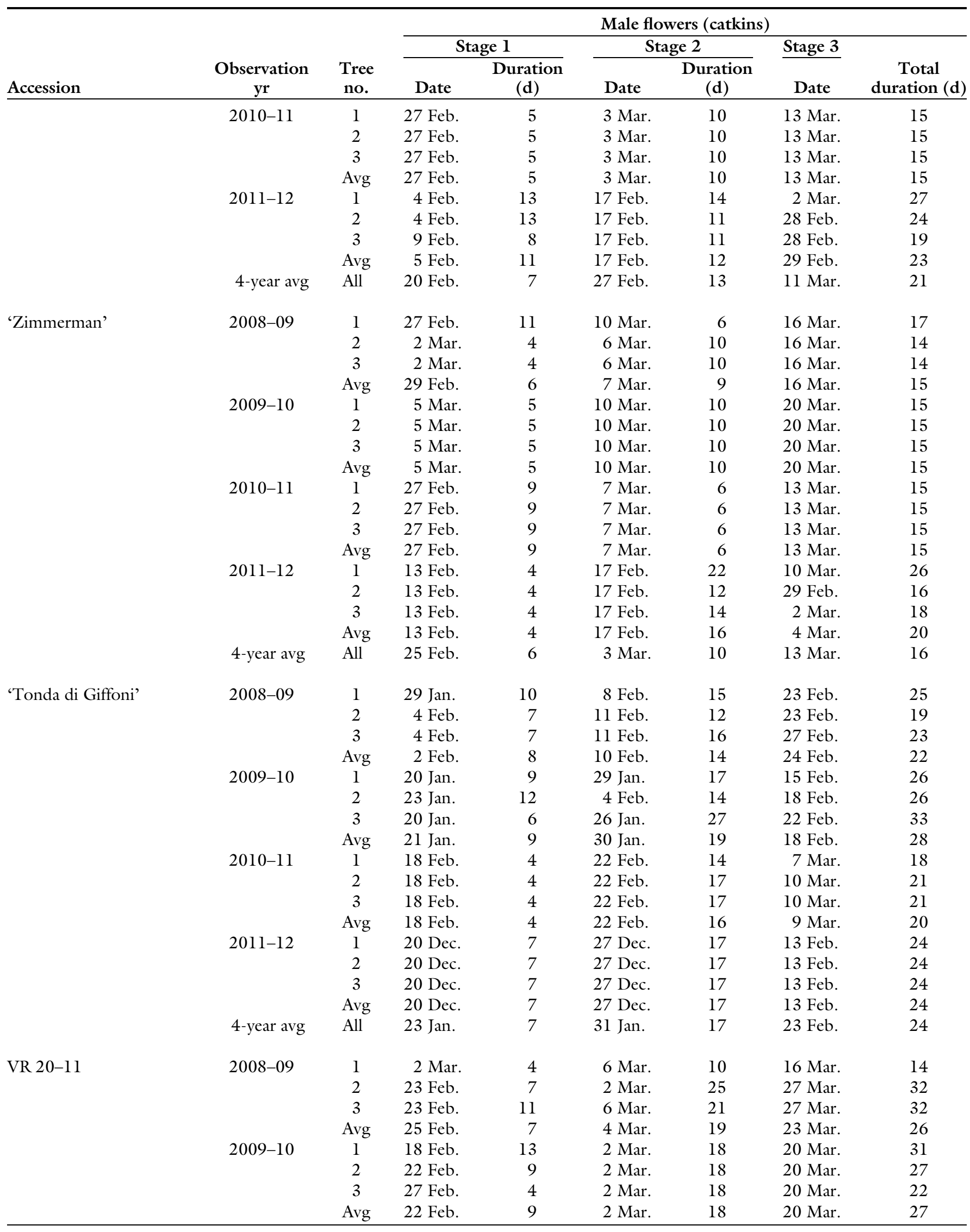

(Continued on next page) 
Supplemental Table 1. (Continued) Pistillate, staminate, and vegetative bloom dates for 19 accessions of hazelnut in New Jersey.

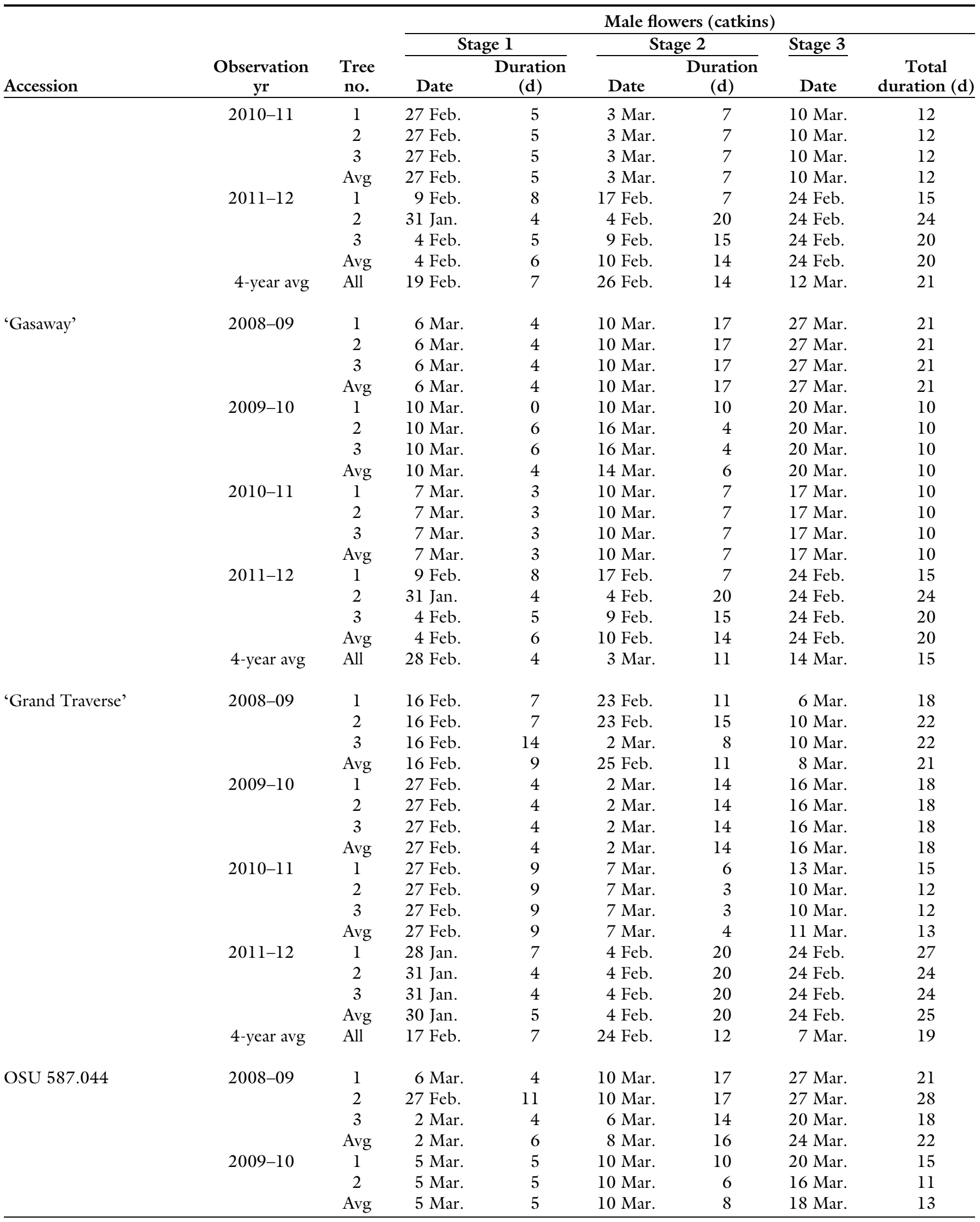


Supplemental Table 1. (Continued) Pistillate, staminate, and vegetative bloom dates for 19 accessions of hazelnut in New Jersey.

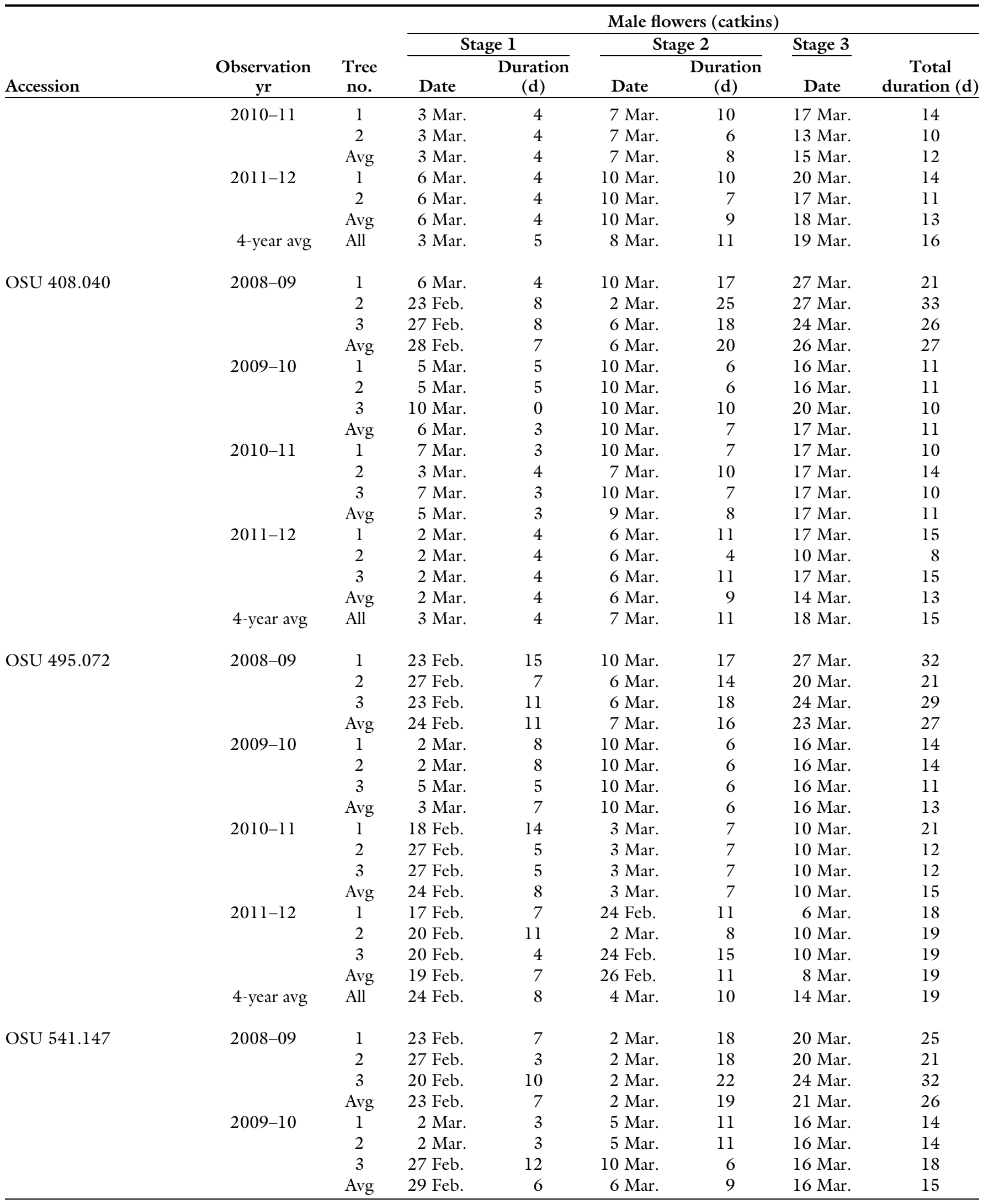

(Continued on next page) 
Supplemental Table 1. (Continued) Pistillate, staminate, and vegetative bloom dates for 19 accessions of hazelnut in New Jersey.

\begin{tabular}{|c|c|c|c|c|c|c|c|c|}
\hline \multirow[b]{3}{*}{ Accession } & \multirow[b]{3}{*}{$\begin{array}{c}\text { Observation } \\
\mathrm{yr}\end{array}$} & \multirow[b]{3}{*}{$\begin{array}{l}\text { Tree } \\
\text { no. }\end{array}$} & \multicolumn{6}{|c|}{ Male flowers (catkins) } \\
\hline & & & \multicolumn{2}{|c|}{ Stage 1} & \multicolumn{2}{|c|}{ Stage 2} & \multirow{2}{*}{$\begin{array}{c}\text { Stage } 3 \\
\text { Date }\end{array}$} & \multirow[b]{2}{*}{$\begin{array}{c}\text { Total } \\
\text { duration }(\mathrm{d})\end{array}$} \\
\hline & & & Date & $\begin{array}{c}\text { Duration } \\
(\mathrm{d})\end{array}$ & Date & $\begin{array}{c}\text { Duration } \\
\text { (d) }\end{array}$ & & \\
\hline & $2010-11$ & 1 & 27 Feb. & 5 & 3 Mar. & 7 & 10 Mar. & 12 \\
\hline & & 2 & 22 Feb. & 10 & 3 Mar. & 7 & 10 Mar. & 17 \\
\hline & & 3 & 22 Feb. & 10 & 3 Mar. & 7 & 10 Mar. & 17 \\
\hline & & 2 & 9 Feb. & 8 & 17 Feb. & 18 & 6 Mar. & 26 \\
\hline & & 3 & 9 Feb. & 8 & 17 Feb. & 18 & 6 Mar. & 26 \\
\hline & & Avg & $10 \mathrm{Feb}$. & 8 & 18 Feb. & 16 & 4 Mar. & 23 \\
\hline & 4-year avg & All & 21 Feb. & 7 & 29 Feb. & 13 & 13 Mar. & 20 \\
\hline \multirow{9}{*}{ 'Ratoli' } & & 2 & 18 Feb. & 9 & 27 Feb. & 7 & 5 Mar. & 16 \\
\hline & & Avg & 18 Feb. & 9 & 27 Feb. & 7 & 5 Mar. & 16 \\
\hline & 2010-11 & 1 & $18 \mathrm{Feb}$ & 9 & 27 Feb. & 12 & 10 Mar. & 21 \\
\hline & & 2 & 18 Feb. & 9 & 27 Feb. & 12 & 10 Mar. & 21 \\
\hline & & Avg & 18 Feb. & 9 & 27 Feb. & 12 & 10 Mar. & 21 \\
\hline & $2011-12$ & 1 & 16 Jan. & 4 & 20 Jan. & 11 & 31 Jan. & 15 \\
\hline & & 2 & 12 Jan. & 4 & 16 Jan. & 15 & 31 Jan. & 19 \\
\hline & & Avg & 14 Jan. & 4 & 18 Jan. & 13 & 31 Jan. & 17 \\
\hline & 4-year avg & All & 6 Feb. & 6 & 13 Feb. & 11 & 23 Feb. & 17 \\
\hline \multirow[t]{5}{*}{ 'Closca Molla' } & 2008-09 & 1 & 16 Feb. & 11 & 27 Feb. & 17 & 16 Mar. & 28 \\
\hline & $2011-12$ & 1 & 20 Jan. & 15 & 4 Feb. & 16 & 20 Feb. & 31 \\
\hline & & 2 & 25 Jan. & 10 & 4 Feb. & 16 & 20 Feb. & 26 \\
\hline & & Avg & 22 Jan. & 13 & 4 Feb. & 16 & 20 Feb. & 29 \\
\hline & 4-year avg & All & 13 Feb. & 11 & 25 Feb. & 12 & 8 Mar. & 23 \\
\hline \multirow[t]{17}{*}{ NADF \#1 (10-50) } & 2008-09 & 1 & 23 Feb. & 15 & 10 Mar. & 14 & 24 Mar. & 29 \\
\hline & & 2 & 6 Mar. & 10 & 16 Mar. & 8 & 24 Mar. & 18 \\
\hline & & 3 & 10 Mar. & 6 & 16 Mar. & 4 & 20 Mar. & 10 \\
\hline & & Avg & 3 Mar. & 10 & 14 Mar. & 9 & 22 Mar. & 19 \\
\hline & $2009-10$ & 1 & 5 Mar. & 12 & 10 Mar. & 6 & 16 Mar. & 18 \\
\hline & & 2 & 5 Mar. & 5 & 10 Mar. & 6 & 16 Mar. & 11 \\
\hline & & 3 & 5 Mar. & 5 & 10 Mar. & 6 & 16 Mar. & 11 \\
\hline & & Avg & 2 Mar. & 7 & 10 Mar. & 6 & 16 Mar. & 13 \\
\hline & 2010-11 & 1 & 27 Feb. & 9 & 7 Mar. & 6 & 13 Mar. & 15 \\
\hline & & 2 & 3 Mar. & 4 & 7 Mar. & 6 & 13 Mar. & 10 \\
\hline & & 3 & 3 Mar. & 4 & 7 Mar. & 6 & 13 Mar. & 10 \\
\hline & & Avg & 1 Mar. & 6 & 7 Mar. & 6 & 13 Mar. & 12 \\
\hline & $2011-12$ & 1 & 9 Feb. & 11 & 20 Feb. & 19 & 10 Mar. & 30 \\
\hline & & 2 & 17 Feb. & 7 & 24 Feb. & 15 & 10 Mar. & 22 \\
\hline & & 3 & 13 Feb. & 11 & 24 Feb. & 15 & 10 Mar. & 26 \\
\hline & & Avg & 13 Feb. & 10 & 22 Feb. & 16 & 10 Mar. & 26 \\
\hline & 4-year avg & All & 27 Feb. & 8 & 6 Mar. & 9 & 15 Mar. & 18 \\
\hline
\end{tabular}


Supplemental Table 1. (Continued) Pistillate, staminate, and vegetative bloom dates for 19 accessions of hazelnut in New Jersey.

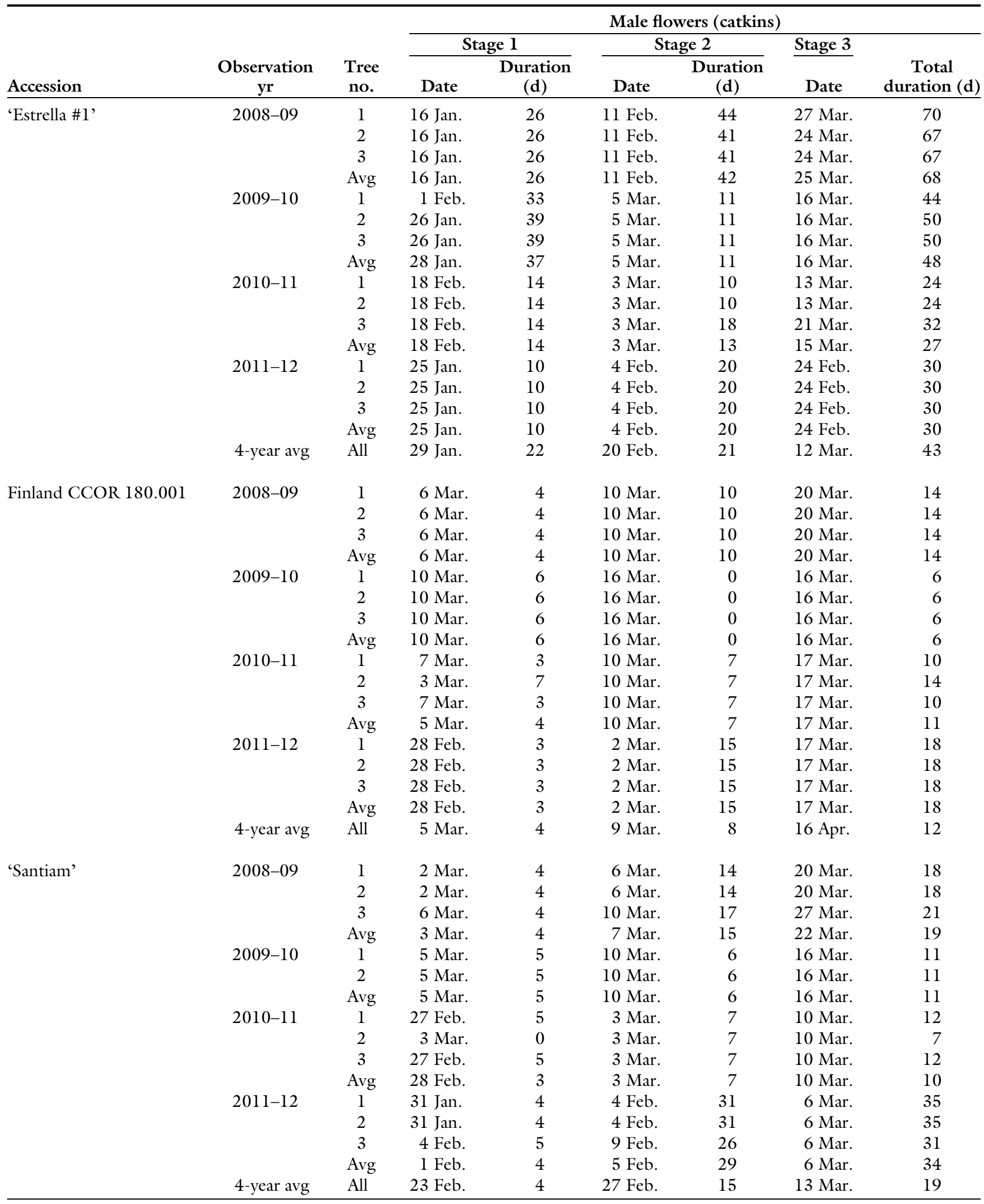

(Continued on next page) 
Supplemental Table 1. (Continued) Pistillate, staminate, and vegetative bloom dates for 19 accessions of hazelnut in New Jersey.

\begin{tabular}{|c|c|c|c|c|c|c|c|c|}
\hline \multirow[b]{3}{*}{ Accession } & \multirow[b]{3}{*}{$\begin{array}{c}\text { Observation } \\
\mathrm{yr}\end{array}$} & \multirow[b]{3}{*}{$\begin{array}{l}\text { Tree } \\
\text { no. }\end{array}$} & \multicolumn{6}{|c|}{ Male flowers (catkins) } \\
\hline & & & \multicolumn{2}{|c|}{ Stage 1} & \multicolumn{2}{|c|}{ Stage 2} & \multirow{2}{*}{$\begin{array}{c}\text { Stage } 3 \\
\text { Date }\end{array}$} & \multirow[b]{2}{*}{$\begin{array}{c}\text { Total } \\
\text { duration }(\mathrm{d})\end{array}$} \\
\hline & & & Date & $\begin{array}{c}\text { Duration } \\
\text { (d) }\end{array}$ & Date & $\begin{array}{l}\text { Duration } \\
\text { (d) }\end{array}$ & & \\
\hline \multirow{11}{*}{ 'Delta' } & 2008-09 & 1 & 2 Mar. & 8 & 10 Mar. & 14 & 24 Mar. & 22 \\
\hline & & 2 & 2 Mar. & 8 & 10 Mar. & 17 & 27 Mar. & 25 \\
\hline & & 3 & 27 Feb. & 4 & 2 Mar. & 14 & 16 Mar. & 18 \\
\hline & & 2 & 5 Mar. & 5 & 10 Mar. & 6 & 16 Mar. & 11 \\
\hline & & 3 & 5 Mar. & 5 & 10 Mar. & 10 & 20 Mar. & 15 \\
\hline & & Avg & 5 Mar. & 5 & 10 Mar. & 7 & 17 Mar. & 12 \\
\hline & $2010-11$ & 1 & 3 Mar. & 4 & 7 Mar. & 6 & 13 Mar. & 10 \\
\hline & & 2 & 3 Mar. & 4 & 7 Mar. & 6 & 13 Mar. & 10 \\
\hline & & 3 & 24 Feb. & 7 & 2 Mar. & 15 & 17 Mar. & 22 \\
\hline & & Avg & 25 Feb. & 6 & 2 Mar. & 16 & 18 Mar. & 22 \\
\hline & 4-year avg & All & 29 Feb. & 6 & 6 Mar. & 11 & 17 Mar. & 17 \\
\hline \multirow[t]{5}{*}{ 'Gamma’ } & 2008-09 & 1 & 6 Mar. & 4 & 10 Mar. & 14 & 24 Mar. & 18 \\
\hline & 2009-10 & 1 & 5 Mar. & 5 & 10 Mar. & 6 & 16 Mar. & 11 \\
\hline & $2010-11$ & 1 & 27 Feb. & 5 & 3 Mar. & 7 & 10 Mar. & 12 \\
\hline & $2011-12$ & 1 & 13 Feb. & 11 & 24 Feb. & 15 & 10 Mar. & 26 \\
\hline & 4-year avg & All & 27 Feb. & 6 & 4 Mar. & 11 & 15 Mar. & 17 \\
\hline 'Epsilon’ & 2008-09 & 1 & 6 Mar. & 4 & 10 Mar. & 10 & 20 Mar. & 14 \\
\hline \multirow[t]{17}{*}{ OSU 526.041} & $2008-09$ & 1 & 24 Mar. & 10 & 3 Apr. & 14 & 17 Apr. & 24 \\
\hline & & 2 & 24 Mar. & 10 & 3 Apr. & 14 & 17 Apr. & 24 \\
\hline & & 3 & 20 Mar. & 11 & 31 Mar. & 17 & 17 Apr. & 28 \\
\hline & & Avg & 22 Mar. & 10 & 2 Apr. & 15 & 17 Apr. & 25 \\
\hline & $2009-10$ & 1 & 16 Mar. & 12 & 28 Mar. & 17 & 14 Apr. & 29 \\
\hline & & 2 & 20 Mar. & 8 & 28 Mar. & 17 & 14 Apr. & 25 \\
\hline & & 3 & 16 Mar. & 17 & 2 Apr. & 12 & 14 Apr. & 29 \\
\hline & & Avg & 17 Mar. & 12 & 29 Mar. & 15 & 14 Apr. & 28 \\
\hline & $2010-11$ & 1 & 4 Apr. & 10 & 14 Apr. & 8 & 22 Apr. & 18 \\
\hline & & 2 & 31 Mar. & 11 & 12 Apr. & 11 & 22 Apr. & 22 \\
\hline & & 3 & 4 Apr. & 10 & 14 Apr. & 8 & 22 Apr. & 18 \\
\hline & & Avg & 2 Apr. & 10 & 13 Apr. & 9 & 22 Apr. & 19 \\
\hline & $2011-12$ & 1 & 17 Mar. & 6 & 23 Mar. & 12 & 4 Apr. & 18 \\
\hline & & 2 & 20 Mar. & 3 & 23 Mar. & 12 & 4 Apr. & 15 \\
\hline & & 3 & 17 Mar. & 6 & 23 Mar. & 8 & 31 Mar. & 14 \\
\hline & & Avg & 18 Mar. & 5 & 23 Mar. & 11 & 2 Apr. & 16 \\
\hline & 4-year avg & All & 22 Mar. & 10 & 1 Apr. & 13 & 13 Apr. & 22 \\
\hline
\end{tabular}

(Continued on next page) 
Supplemental Table 1. (Continued) Pistillate, staminate, and vegetative bloom dates for 19 accessions of hazelnut in New Jersey.

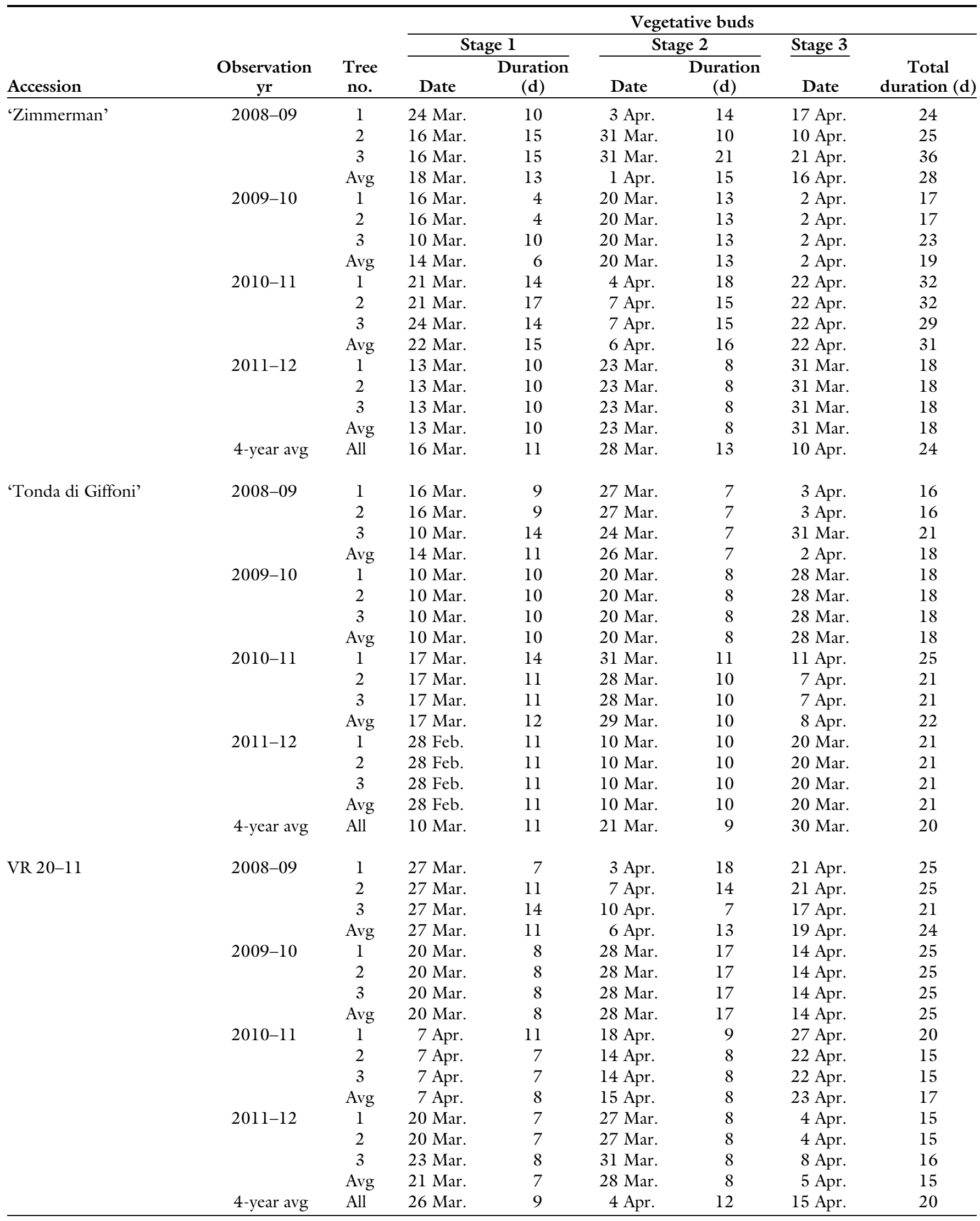


Supplemental Table 1. (Continued) Pistillate, staminate, and vegetative bloom dates for 19 accessions of hazelnut in New Jersey.

\begin{tabular}{|c|c|c|c|c|c|c|c|c|}
\hline \multirow[b]{3}{*}{ Accession } & \multirow[b]{3}{*}{$\begin{array}{c}\text { Observation } \\
\mathrm{yr}\end{array}$} & \multirow[b]{3}{*}{$\begin{array}{l}\text { Tree } \\
\text { no. }\end{array}$} & \multicolumn{6}{|c|}{ Vegetative buds } \\
\hline & & & \multicolumn{2}{|c|}{ Stage 1} & \multicolumn{2}{|c|}{ Stage 2} & \multirow{2}{*}{$\begin{array}{c}\text { Stage } 3 \\
\text { Date }\end{array}$} & \multirow[b]{2}{*}{$\begin{array}{c}\text { Total } \\
\text { duration }(\mathrm{d}\end{array}$} \\
\hline & & & Date & $\begin{array}{c}\text { Duration } \\
\text { (d) }\end{array}$ & Date & $\begin{array}{c}\text { Duration } \\
(\mathrm{d})\end{array}$ & & \\
\hline \multirow[t]{11}{*}{ ‘Gasaway' } & 2008-09 & 1 & 31 Mar. & 17 & 17 Apr. & 10 & 27 Apr. & 27 \\
\hline & & 2 & 7 Apr. & 14 & 21 Apr. & 9 & 30 Apr. & 23 \\
\hline & & 3 & 31 Mar. & 21 & 21 Apr. & 6 & 27 Apr. & 27 \\
\hline & & 2 & 2 Apr. & 15 & 17 Apr. & 7 & 24 Apr. & 22 \\
\hline & & 3 & 2 Apr. & 15 & 17 Apr. & 7 & 24 Apr. & 22 \\
\hline & & Avg & 2 Apr. & 15 & 17 Apr. & 6 & 23 Apr. & 21 \\
\hline & $2010-11$ & 1 & 14 Apr. & 13 & 27 Apr. & 3 & 30 Apr. & 16 \\
\hline & & 2 & 14 Apr. & 8 & 22 Apr. & 8 & 30 Apr. & 16 \\
\hline & & 3 & 8 Apr. & 9 & 17 Apr. & 4 & 21 Apr. & 13 \\
\hline & & Avg & 6 Apr. & 9 & 15 Apr. & 4 & 19 Apr. & 13 \\
\hline & 4-year avg & All & 6 Apr. & 13 & 18 Apr. & 7 & 25 Apr. & 19 \\
\hline \multirow[t]{9}{*}{ 'Grand Traverse' } & 2008-09 & 1 & 31 Mar. & 13 & 13 Apr. & 11 & 24 Apr. & 24 \\
\hline & & 2 & 31 Mar. & 10 & 10 Apr. & 11 & 21 Apr. & 21 \\
\hline & & 3 & 3 Apr. & 10 & 13 Apr. & 11 & 24 Apr. & 21 \\
\hline & & Avg & 1 Apr. & 11 & 12 Apr. & 11 & 23 Apr. & 22 \\
\hline & 2009-10 & 1 & 20 Mar. & 21 & 10 Apr. & 11 & 21 Apr. & 32 \\
\hline & & 2 & 20 Mar. & 25 & 14 Apr. & 7 & $21 \mathrm{Apr}$. & 32 \\
\hline & & 3 & 20 Mar. & 25 & 14 Apr. & 10 & 24 Apr. & 35 \\
\hline & & Avg & 23 Mar. & 12 & 4 Apr. & 5 & 9 Apr. & 17 \\
\hline & 4-year avg & All & 28 Mar. & 14 & 11 Apr. & 9 & 20 Apr. & 23 \\
\hline \multirow[t]{14}{*}{ OSU 587.044} & 2008-09 & 1 & 27 Mar. & 14 & 10 Apr. & 14 & 24 Apr. & 28 \\
\hline & & 2 & 31 Mar. & 10 & 10 Apr. & 11 & 21 Apr. & 21 \\
\hline & & 3 & 20 Mar. & 18 & 7 Apr. & 14 & 21 Apr. & 32 \\
\hline & & Avg & 26 Mar. & 14 & 9 Apr. & 13 & 22 Apr. & 27 \\
\hline & $2009-10$ & 1 & 16 Mar. & 12 & 28 Mar. & 24 & 21 Apr. & 36 \\
\hline & & 2 & 16 Mar. & 17 & 2 Apr. & 22 & 24 Apr. & 39 \\
\hline & & Avg & 16 Mar. & 15 & 30 Mar. & 23 & 22 Apr. & 38 \\
\hline & $2010-11$ & 1 & 11 Apr. & 7 & 18 Apr. & 9 & 27 Apr. & 16 \\
\hline & & 2 & 11 Apr. & 11 & 22 Apr. & 5 & 27 Apr. & 16 \\
\hline & & Avg & 11 Apr. & 9 & 20 Apr. & 7 & 27 Apr. & 16 \\
\hline & $2011-12$ & 1 & 20 Mar. & 11 & 31 Mar. & 8 & 8 Apr. & 19 \\
\hline & & 2 & 23 Mar. & 8 & 31 Mar. & 8 & 8 Apr. & 16 \\
\hline & & Avg & 21 Mar. & 10 & 31 Mar. & 8 & 8 Apr. & 18 \\
\hline & 4-year avg & All & 26 Mar. & 12 & 7 Apr. & 13 & 20 Apr. & 25 \\
\hline
\end{tabular}

(Continued on next page) 
Supplemental Table 1. (Continued) Pistillate, staminate, and vegetative bloom dates for 19 accessions of hazelnut in New Jersey.

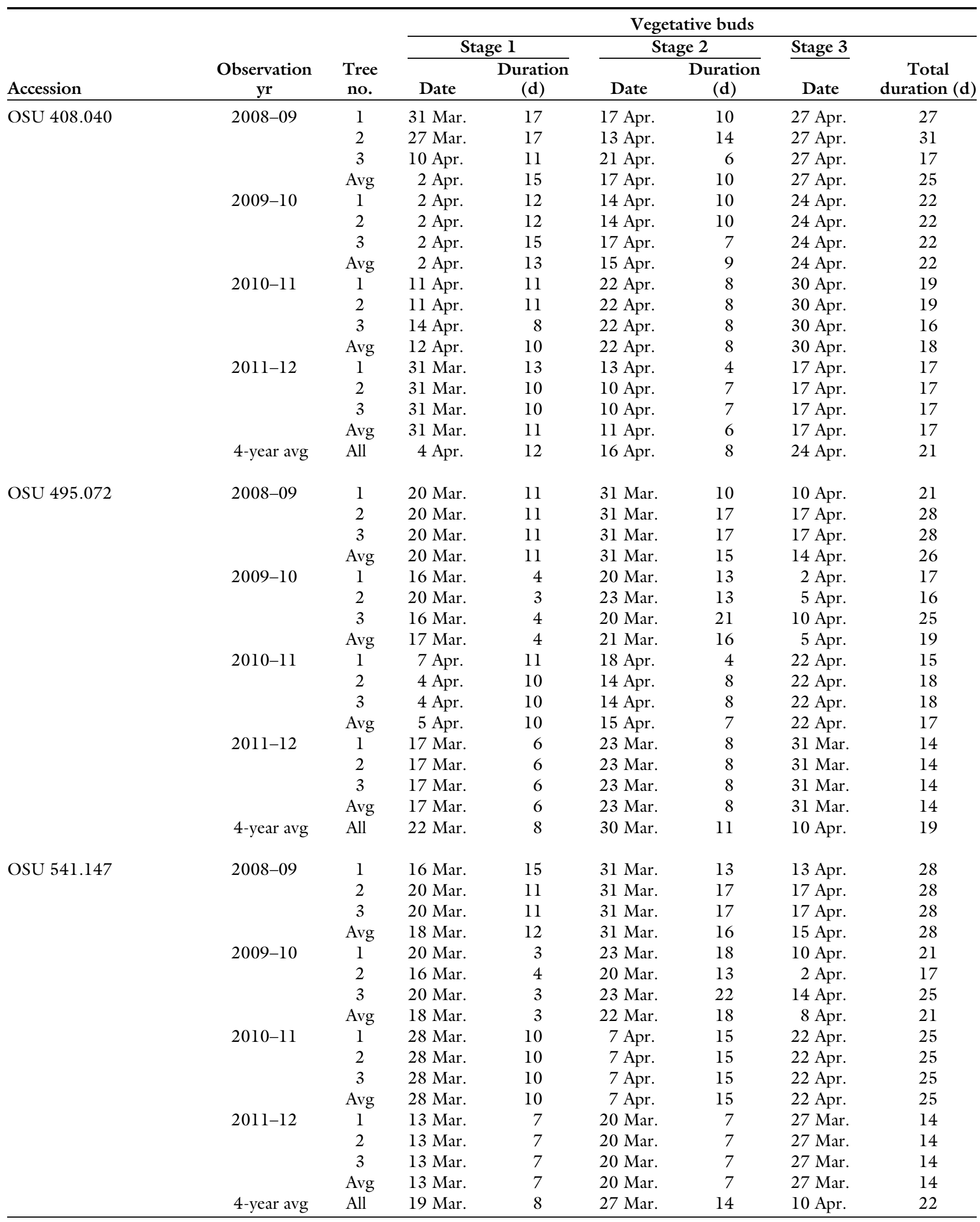

(Continued on next page) 
Supplemental Table 1. (Continued) Pistillate, staminate, and vegetative bloom dates for 19 accessions of hazelnut in New Jersey.

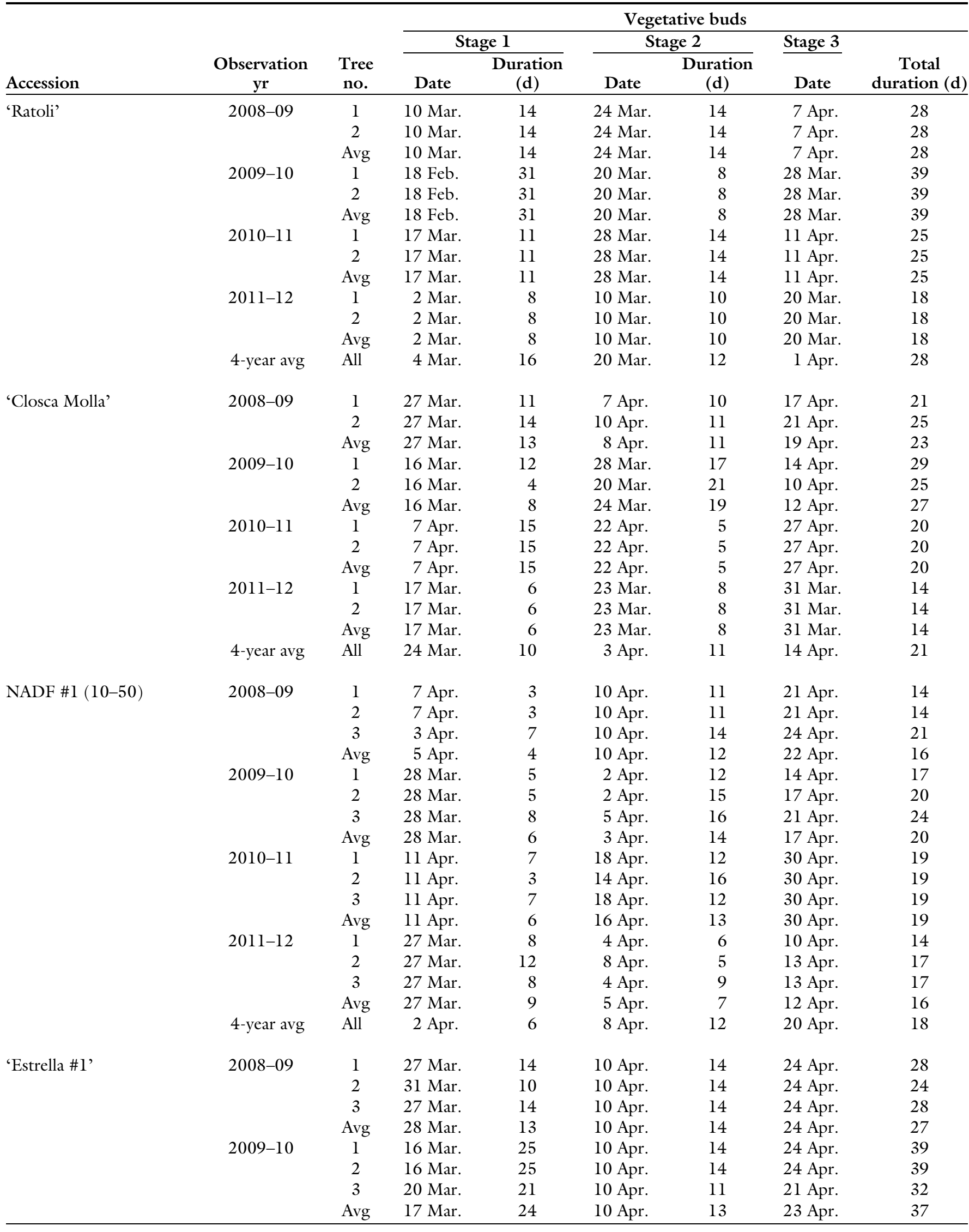

(Continued on next page) 
Supplemental Table 1. (Continued) Pistillate, staminate, and vegetative bloom dates for 19 accessions of hazelnut in New Jersey.

\begin{tabular}{|c|c|c|c|c|c|c|c|c|}
\hline \multirow[b]{3}{*}{ Accession } & \multirow[b]{3}{*}{$\begin{array}{c}\text { Observation } \\
\mathrm{yr}\end{array}$} & \multirow[b]{3}{*}{$\begin{array}{c}\text { Tree } \\
\text { no. }\end{array}$} & \multicolumn{6}{|c|}{ Vegetative buds } \\
\hline & & & \multicolumn{2}{|c|}{ Stage 1} & \multicolumn{2}{|c|}{ Stage 2} & \multirow{2}{*}{$\begin{array}{c}\text { Stage } 3 \\
\text { Date }\end{array}$} & \multirow[b]{2}{*}{$\begin{array}{c}\text { Total } \\
\text { duration }(\mathrm{d}\end{array}$} \\
\hline & & & Date & $\begin{array}{c}\text { Duration } \\
(\mathrm{d})\end{array}$ & Date & $\begin{array}{c}\text { Duration } \\
(\mathrm{d})\end{array}$ & & \\
\hline & $2010-11$ & 1 & 7 Apr. & 11 & 18 Apr. & 9 & 27 Apr. & 20 \\
\hline & & 2 & 7 Apr. & 11 & 18 Apr. & 9 & 27 Apr. & 20 \\
\hline & & 3 & 7 Apr. & 15 & 22 Apr. & 8 & 30 Apr. & 23 \\
\hline & & 2 & 20 Mar. & 11 & 31 Mar. & 8 & 8 Apr. & 19 \\
\hline & & 3 & 20 Mar. & 11 & 31 Mar. & 8 & 8 Apr. & 19 \\
\hline & & Avg & 20 Mar. & 11 & 31 Mar. & 8 & 8 Apr. & 19 \\
\hline & 4-year avg & All & 25 Mar. & 15 & 9 Apr. & 11 & 20 Apr. & 26 \\
\hline & $2009-10$ & 1 & 16 Mar. & 29 & 14 Apr. & 7 & 21 Apr. & 36 \\
\hline & & 2 & 20 Mar. & 25 & 14 Apr. & 14 & 28 Apr. & 39 \\
\hline & & 3 & 20 Mar. & 25 & 14 Apr. & 10 & 24 Apr. & 35 \\
\hline & & Avg & 18 Mar. & 26 & 14 Apr. & 10 & 24 Apr. & 37 \\
\hline & $2010-11$ & 1 & 11 Apr. & 7 & 18 Apr. & 9 & 27 Apr. & 16 \\
\hline & & 2 & 11 Apr. & 11 & 22 Apr. & 5 & 27 Apr. & 16 \\
\hline & & 3 & 11 Apr. & 7 & 18 Apr. & 9 & 27 Apr. & 16 \\
\hline & & Avg & 11 Apr. & 8 & 19 Apr. & 8 & 27 Apr. & 16 \\
\hline & $2011-12$ & 1 & 4 Apr. & 4 & 8 Apr. & 9 & 17 Apr. & 13 \\
\hline & & 2 & 4 Apr. & 4 & 8 Apr. & 9 & 17 Apr. & 13 \\
\hline & & 3 & 4 Apr. & 6 & 10 Apr. & 7 & 17 Apr. & 13 \\
\hline & & 2 & 20 Mar. & 13 & 2 Apr. & 12 & 14 Apr. & 25 \\
\hline & & Avg & 20 Mar. & 11 & 30 Mar. & 15 & 14 Apr. & 25 \\
\hline & 2010-11 & 1 & 11 Apr. & 7 & 18 Apr. & 9 & 27 Apr. & 16 \\
\hline & & 2 & 4 Apr. & 10 & 14 Apr. & 8 & 22 Apr. & 18 \\
\hline & & 3 & 7 Apr. & 11 & 18 Apr. & 9 & 27 Apr. & 20 \\
\hline & & Avg & 7 Apr. & 9 & 16 Apr. & 9 & 25 Apr. & 18 \\
\hline & $2011-12$ & 1 & 20 Mar. & 11 & 31 Mar. & 4 & 4 Apr. & 15 \\
\hline & & 2 & 23 Mar. & 8 & 31 Mar. & 8 & 8 Apr. & 16 \\
\hline & & 3 & 20 Mar. & 7 & 27 Mar. & 8 & 4 Apr. & 15 \\
\hline & & Avg & 21 Mar. & 9 & 29 Mar. & 7 & 5 Apr. & 15 \\
\hline & 4-year avg & All & 27 Mar. & 9 & 5 Apr. & 11 & 16 Apr. & 20 \\
\hline \multirow[t]{8}{*}{ 'Delta' } & 2008-09 & 1 & 27 Mar. & 21 & 17 Apr. & 7 & 24 Apr. & 28 \\
\hline & & 2 & 31 Mar. & 13 & 13 Apr. & 11 & 24 Apr. & 24 \\
\hline & & 3 & 31 Mar. & 10 & 10 Apr. & 14 & 24 Apr. & 24 \\
\hline & & Avg & 29 Mar. & 15 & 13 Apr. & 11 & 24 Apr. & 25 \\
\hline & $2009-10$ & 1 & 16 Mar. & 25 & 10 Apr. & 11 & 21 Apr. & 36 \\
\hline & & 2 & 16 Mar. & 25 & 10 Apr. & 11 & 21 Apr. & 36 \\
\hline & & 3 & 16 Mar. & 25 & 10 Apr. & 11 & 21 Apr. & 36 \\
\hline & & Avg & 16 Mar. & 25 & 10 Apr. & 11 & 21 Apr. & 36 \\
\hline
\end{tabular}

(Continued on next page) 


\section{Research Reports}

Supplemental Table 1. (Continued) Pistillate, staminate, and vegetative bloom dates for 19 accessions of hazelnut in New Jersey.

\begin{tabular}{|c|c|c|c|c|c|c|c|c|}
\hline \multirow[b]{3}{*}{ Accession } & \multirow[b]{3}{*}{$\begin{array}{c}\text { Observation } \\
\mathrm{yr}\end{array}$} & \multirow[b]{3}{*}{$\begin{array}{c}\text { Tree } \\
\text { no. }\end{array}$} & \multicolumn{6}{|c|}{ Vegetative buds } \\
\hline & & & \multicolumn{2}{|c|}{ Stage 1} & \multicolumn{2}{|c|}{ Stage 2} & \multirow{2}{*}{$\begin{array}{c}\text { Stage } 3 \\
\text { Date }\end{array}$} & \multirow[b]{2}{*}{$\begin{array}{c}\text { Total } \\
\text { duration }(\mathrm{d})\end{array}$} \\
\hline & & & Date & $\begin{array}{c}\text { Duration } \\
\text { (d) }\end{array}$ & Date & $\begin{array}{c}\text { Duration } \\
\text { (d) }\end{array}$ & & \\
\hline & $2010-11$ & 1 & 7 Apr. & 11 & 18 Apr. & 9 & 27 Apr. & 20 \\
\hline & & 2 & 7 Apr. & 11 & 18 Apr. & 9 & 27 Apr. & 20 \\
\hline & & 3 & 4 Apr. & 10 & 14 Apr. & 8 & 22 Apr. & 18 \\
\hline & & 2 & 4 Apr. & 4 & 8 Apr. & 5 & 13 Apr. & 9 \\
\hline & & 3 & 27 Mar. & 12 & 8 Apr. & 5 & 13 Apr. & 17 \\
\hline & & Avg & 29 Mar. & 8 & 6 Apr. & 8 & 14 Apr. & 16 \\
\hline & 4-year avg & All & 28 Mar. & 15 & 11 Apr. & 10 & 21 Apr. & 24 \\
\hline & 4-year avg & All & 26 Mar. & 12 & 7 Apr. & 9 & 16 Apr. & 21 \\
\hline 'Epsilon' & 2008-09 & 1 & 20 Mar. & 11 & 31 Mar. & 17 & 17 Apr. & 28 \\
\hline & 2009-10 & 1 & 10 Mar. & 10 & 20 Mar. & 13 & 2 Apr. & 23 \\
\hline & $2010-11$ & 1 & 13 Mar. & 22 & 4 Apr. & 18 & 22 Apr. & 40 \\
\hline & $2011-12$ & 1 & 13 Mar. & 7 & 20 Mar. & 7 & 27 Mar. & 14 \\
\hline & 4-year avg & All & 14 Mar. & 13 & 26 Mar. & 14 & 9 Apr. & 26 \\
\hline
\end{tabular}

